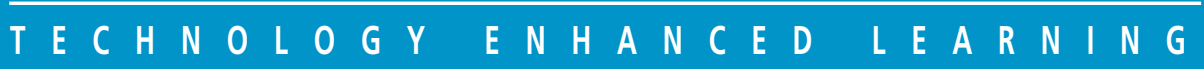

\title{
The Art \& Science of Learning Design
}

Marcelo Maina, Brock Craft and Yishay Mor (Eds.)

Sense Publishers 
The Art \& Science of Learning Design 


\title{
TECHNOLOGY ENHANCED LEARNING Volume 9
}

\author{
Series Editors \\ Richard Noss, London Knowledge Lab, IOE, UK \\ Mike Sharples, Learning Sciences Research Institute, University of Nottingham, UK
}

\section{Editorial Board}

Nicolas Balacheff, CNRS, France

R.M. Bottino, Consiglio Nazionale delle Ricerche, Istituto Tecnologie Didattiche, Genova, Italy

Tak-Wai Chan,Graduate Institute of Network Learning Technology at the National Central University of Taiwan

Peter Goodyear, CoCo, Faculty of Education \& Social Work, University of Sydney

Miguel Nussbaum, Escuela de Ingeniería, Pontificia Universidad Católica de Chile

Jeremy Roschelle, SRI International, USA

Barbara Wasson, University of Bergen, Norway

\section{Scope}

The rapid co-evolution of technology and learning is offering new ways to represent knowledge, new educational practices, and new global communities of learners. Yet the contribution of these changes to formal education is largely unexplored, along with possibilities for deepening our understanding of what and how to learn. Similarly, the convergence of personal technologies offers new opportunities for informal, conversational and situated learning. But this is widening the gulf between everyday learning and formal education, which is struggling to adapt pedagogies and curricula that were established in a pre-digital age.

This series, Technology Enhanced Learning, will explore learning futures that incorporate digital technologies in innovative and transformative ways. It will elaborate issues including the design of learning experiences that connect formal and informal contexts; the evolution of learning and technology; new social and cultural contexts for learning with technology; novel questions of design, computational expression, collaboration and intelligence; social exclusion and inclusion in an age of personal and mobile technology; and attempts to broaden practical and theoretical perspectives on cognition, community and epistemology.

The series will be of interest to researchers and students in education and computing, to educational policy makers, and to the general public with an interest in the future of learning with technology. 


\title{
The Art \& Science of Learning Design
}

\author{
Edited by
}

\section{Marcelo Maina}

University of Catalonia, Barcelona, Spain

Brock Craft

Goldsmiths, University of London, UK

and

Yishay Mor

PAU Education, Barcelona, Spain

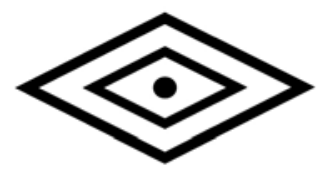

SENSE PUBLISHERS

ROTTERDAM/BOSTON/TAIPEI 
A C.I.P. record for this book is available from the Library of Congress.

ISBN: 978-94-6300-101-4 (paperback)

ISBN: 978-94-6300-102-1 (hardback)

ISBN: 978-94-6300-103-8 (e-book)

Published by: Sense Publishers,

P.O. Box 21858,

3001 AW Rotterdam,

The Netherlands

https://www.sensepublishers.com/

Printed on acid-free paper

All Rights Reserved (C) 2015 Sense Publishers

No part of this work may be reproduced, stored in a retrieval system, or transmitted in any form or by any means, electronic, mechanical, photocopying, microfilming, recording or otherwise, without written permission from the Publisher, with the exception of any material supplied specifically for the purpose of being entered and executed on a computer system, for exclusive use by the purchaser of the work. 


\section{TABLE OF CONTENTS}

Preface

Introduction: Learning Design: Definitions, Current Issues and Grand Challenges

ix

Yishay Mor, Brock Craft and Marcelo Maina

\section{Section 1: Theories}

1. Reflections on the Art and Science of Learning Design and the Larnaca Declaration James Dalziel

2. Analysing the Structural Properties of Learning Networks: Architectural Insights into Buildable Forms

Peter Goodyear, Kate Thompson, David Ashe, Ana Pinto, Lucila Carvalho, Martin Parisio, Paul Parker, Beat Schwendimann, Dewa Wardak and

Pippa Yeoman

3. Concretization of Design Ideas in the Context of Educational Technology Design

Tamar Ronen-Fuhrmann and Yael Kali

4. A Multi-Dimensional Space for Learning Design Representations and Tools

Francesca Pozzi, Donatella Persico and Jeffrey Earp

\section{Section 2: Methods}

5. Toward Relevant and Usable TEL Research

Susan McKenney

6. Introducing the Collaborative e-Learning Design Method (COED)

Thomas Ryberg, Lillian Buus, Tom Nyvang, Marianne Georgsen and Jacob Davidsen

7. Double Loop Design: Configuring Narratives, Patterns and Scenarios in the Design of Technology Enhanced Learning

Steven Warburton and Yishay Mor

8. Towards a Principled Approach to Evaluating Learning

Design Tools: From Proof of Concept to Evidence of Impact 


\section{TABLE OF CONTENTS}

9. Why Has IMS Learning Design Not LED to the Advances Which Were Hoped for?

Timothy Goddard, David Griffiths and Wang Mi

10. A Critical Review of IMS Learning Design: Recommendations for a Revised Version

Daniel Burgos

\section{Section 3: Tools}

11. OpenGLM: Integrating Open Educational Resources in IMS Learning Design Authoring

Michael Derntl

12. Reflections on Developing a Tool for Creating Visual

Representations of Learning Designs: Towards a Visual Language for Learning Designs

Andrew Brasher and Simon Cross

13. The e-Design Template: A Pedagogic Guide for e-Learning Designers Helen Walmsley

14. LdShake and the "Biologia en Context" Teacher Community across High Schools

Davinia Hernández-Leo, Pau Moreno, Mar Carrió, Jonathan Chacón and Josep Blat

15. ISiS and ScenEdit: An Intention-Oriented Learning Design

Framework

Valérie Emin and Jean-Philippe Pernin 


\section{PREFACE}

The Art and Science of Learning Design (ASLD) workshop ${ }^{1}$ was convened in October 2011 in London, UK, to explore the tools, methods, and frameworks available for practitioners and researchers interested in designing for learning, and to articulate the challenges in this emerging domain. The workshop adopted an unconventional design, whereby contributions were shared online beforehand, and the event itself was dedicated to synergy and synthesis. In a novel bid to make the workshop as open as possible, to external as well as on-site participants, social media tools were employed to support dissemination contemporaneously with the events at the workshop. Participants were encouraged to write collaboratively and critique online, to use twitter, and to contribute to workshop sessions in cloudWorks, ${ }^{2}$ a social networking site for finding, sharing and discussing learning and teaching ideas and designs.

The present volume is based on the outcomes of the ASLD workshop and the debates that followed since, including the special issue of Research in Learning Technology (Mor \& Craft, 2012; Mor, Craft, \& Hernández-Leo, 2013), and is organised according to some of the thematic strands that were used to structure it. In this introductory chapter, we present the field of Learning Design ${ }^{3}$ and the topical themes of the workshop. We begin by presenting and comparing the common definitions of Learning Design (LD), and clarifying its links to the related but distinct field of Instructional Design (ID). We then relate conceptions of Learning Design to the structure of the book. We explore its relevance and value to the stakeholders of Learning Design by highlighting some of its current issues and challenges. We conclude with an overview of the chapters in this book, relating them to these key thematic strands of Learning Design and its grand challenges.

\section{NOTES}

http://www.ld-grid.org/workshops/ASLD11

Topics on Cloudworks are organised as "clouds" and "cloudscapes". The ASLD workshop clouds, comprising comments, discussions, notes and the accepted peer-reviewed papers can be found within the ASLD cloudscape: http://cloudworks.ac.uk/cloudscape/view/2349

3 We use Learning Design (capitalised) to refer to the field, and learning design to refer to the act of designing for learning or its outputs. 



\title{
YISHAY MOR, BROCK CRAFT AND MARCELO MAINA
}

\author{
INTRODUCTION \\ Learning Design: Definitions, Current Issues and \\ Grand Challenges
}

\section{BACKGROUND}

We live in an era defined by a wealth of open and readily available information, and the accelerated evolution of social, mobile and creative technologies. The provision of knowledge, once a primary role of educators, is now devolved to an immense web of free and readily accessible sources. Consequently, educators need to redefine their role not just "from sage on the stage to guide on the side" (King, 1993) but, as more and more voices insist, as "designers for learning" (Goodyear $\&$ Dimitriadis, 2013). Adopting a designer mindset means using empathy and observation to understand where the learners are, and creating the things that will help them get to where you want them to be, be those tasks, resources, social configurations or tools. These are exciting times for educators, but they also entail increasingly complex challenges. Educators may still provide access to information, yet now they also need to carefully craft the conditions for learners to enquire, explore, analyse, synthesise and collaboratively construct their knowledge from the variety of technological resources available to them. This is particularly important in a climate where information is dynamic and rapidly changing, needs to be contextualised, and where an authoritative voice is needed. As Laurillard (2013, p. 2) observes, "If we are confident in our use of technology then we can go beyond mere awareness to full exploitation of these new opportunities." The bleak alternative is that educators are left behind and dis-empowered from shaping new paradigms of learning.

The call for such a repositioning of educators is heard from leaders in the field of technology-enhanced learning (TEL) and resonates well with the growing culture of design-based research in Education. However, it is still struggling to find a foothold in educational practice. We contend that the root causes of this discrepancy are the lack of articulation of design practices and methods, and a shortage of tools and representations to support such practices, a lack of a culture of teacher-as-designer among practitioners, and insufficient theoretical development to substantiate this. 


\section{DEFINING LEARNING DESIGN}

The field of Learning Design, or as some would argue Design for Learning (Beetham \& Sharpe, 2013; Laurillard, 2013), emerged from a growing recognition that the role of educators is, as Diana Laurillard phrases it: "not to transmit knowledge to a passive recipient, but to structure the learner's engagement with the knowledge, practising the high-level cognitive skills that enable them to make that knowledge their own" (Laurillard, 2008, p. 527). This view positions educational practice as an act of design, not in the artistic meaning of the word but in the sense of "as a goaldirected, problem solving activity that results in the creation of something useful that did not exist before" (Ertmer, Parisio, \& Wardak, 2013). Or, as Herbert Simon declared: "Everyone designs who devises courses of action aimed at changing existing situations into preferred ones" (Simon, 1996, p. 111).

Mor and Craft (2012) define learning design as "the creative and deliberate act of devising new practices, plans of activity, resources and tools aimed at achieving particular educational aims in a given context" (p. 86). Adding that it should be informed by subject knowledge, pedagogical theory, technological know-how, and practical experience and at the same time, it should also engender innovation in all these domains and support learners in their efforts and aims.

The qualifiers "creative and deliberate" above reflect the dual nature of design (and in particular learning design) as both art and science. This positioning is informed by theoretical studies of the nature and value of design (Cross, 2001; Latour, 2008; Schön, 1992). Arguably, if we wish to develop a productive understanding of the term learning design, we should begin with a careful consideration of its constituents: "learning" and "design". There is a general agreement that learning is a fundamental capacity of humans. Yet, this capacity is so fundamental that the way it is conceptualised is contingent on the observer's framework of choice for examining human behaviour. In a landmark article, Andy Clark (2013) describes the fundamental function of the brain as predictive machine: one that uses past experiences and current sensory input to generate expectations for future sensory inputs, and then evaluates the error, or discrepancy between these expectations and the inputs eventually observed. Learning, in this perspective, is the minimisation of the error between expectations and observations. Different perspectives will yield a different conceptualisation of learning: as a change of intentional state or a change of practice - individual and social. But one element is common to all: a change in human condition. However, whereas learning is an inate human capacity, education is about directing learning towards specified objectives. Hence, as argued above, it is a domain of design.

How do we understand design? Holmberg (2014) provides an insightful discussion, juxtaposing Simon's view with Schön's. Both Simon and Schön, argues Holmberg, see teachers (and other practitioners) as designers who devise new methods and artefacts to solve problems. Yet, while Simon sees design as a rational process of problem-solving by iterative optimisation, Schön places a greater emphasis 
on the process of problem-setting. It is important to note both the commonalities and the tensions between these approaches. On the common side, design is seen as a simultaneous creative practice and a process of inquiry. It operates in complex domains, where analytical techniques often fail - and hence has to apply iterative "generate and test" methods. The difference between Simon and Schön, argues Holmberg, is that while Simon takes a positivist, "technical rationality" stance, Schön adopts a pragmatist-construtivist view. Simon holds that even ill-structured problems can be decomposed into structured ones which can be solved systematically by applying scientific principles. Schön, on the other hand, attributes much greater value to the tacit knowledge of practitioners. Real-world domains are uncertain, ambiguous, ill-defined and complex. Often the problem to be solved is only fully understood when the solution is presented. In other words, articulating the problem is half the solution - but not necessarily the first half. Following Schön, Holmberg suggests that rather than seeing design as the application of scientific principles in a practical setting, a more balanced approach is in order - in which practitioners are seen as "on-the-spot researchers", informed and informing scientists through a continuous dialogue. This proposal resonates with the ideas of teacher inquiry and design inquiry of learning, discussed below.

Mor, Craft, and Hernández-Leo (2013) consider Latour's insights on design (Latour, 2008), and their projection into learning design. Latour lists "advantages" of design: humility, attentiveness to detail, semiotic skills, remedial intent and an ethical dimension. When combined with the observations above, we derive the following assertions:

Learning design is...

- A process by which practitioners aim to achieve educational aims in a given context.

- An art: a skilled craftsmanship and creative practice.

- A science: a critical and reflective inquiry informed by theory.

- Ethically driven: education strives to make the world better, hence Learning design is tasked with understanding what "better" means, and how to get there.

- Change-oriented: responding to a changing world, realising that doing the same as before will not achieve the same results - but doing things differently can achieve better results.

- Iterative: considering the current state of affairs, perturbing it with innovations, observing the changes that ensue and repeating.

- Interleaving problem-setting and problem-solving: as we change the environment in which we operate, our understanding of that environment changes, and consequently so do our desires within it.

- Humble: acknowledging the limitations of real-world settings, and acknowledging our limitations as actors within those settings.

Admittedly, these qualifiers are a step beyond the common definitions of learning design. While we are confident that most of the experts in the field would 
not disagree with these statements, the definitions offered in the literature are much narrower.

The Larnaca declaration (Daziel, this volume chapter 1; Dalziel et al., 2013) provides an extensive (if admittedly, not comprehensive) timeline of the field of Learning Design. It traces the origins of the field to four strands of work in the early 2000's, mainly in the Netherlands, the UK and Australia. The Larnaca declaration states:

The new field of Learning Design seeks to develop a descriptive framework for teaching and learning activities ("educational notation"), and to explore how this framework can assist educators to share and adopt great teaching ideas.

This definition highlights the issue of representation, as reflected in Koper's (2006, p. 13) definition:

A 'learning design' is defined as the description of the teaching-learning process that takes place in a unit of learning (e.g., a course, a lesson or any other designed learning event). The key principle in learning design is that it represents the learning activities and the support activities that are performed by different persons (learners, teachers) in the context of a unit of learning.

Yet the work of Koper and his colleagues, first on EML and later of the specification of IMS-LD, focused on machine readable representations, which would support the automation of learning design and delivery systems. By contrast, the Larnaca declaration also acknowledges the importance of sharing effective teaching innovations among practitioners, as expressed in Conole's definition (2013, p. 121):

A methodology for enabling teachers/designers to make more informed decisions in how they go about designing learning activities and interventions, which is pedagogically informed and makes effective use of appropriate resources and technologies. This includes the design of resources and individual learning activities right up to curriculum-level design. A key principle is to help make the design process more explicit and shareable. Learning Design as an area of research and development includes both gathering empirical evidence to understand the design process, as well as the development of a range of learning design resource, tools and activities.

Koper and Conole suggest two seemingly competing approaches. Falconer, Finlay and Fincher (2011) note that Learning Design has two roots in technology enhanced learning (TEL). The first is the construction of computer systems to orchestrate the delivery of learning resources and activities for computer-assisted learning. The second is in the need to find effective ways of sharing innovation in TEL practice, providing an aid to efficiency and professional development for teachers. Koper's definition above represents the first tradition, while Conole's is derived from the second. Note also, that Conole considers design as a verb - the process of innovation, 
whereas Koper refers to the noun - the product of this process. Yet both of these definitions side-step the issue of design knowledge, its formulation, communication, critique, aggregation and application. This has been a central concern of the design patterns and design principles traditions, discussed below. The discussions at the ASLD workshop and the chapters in this volume indicate a growing recognition of the need for dialogue across these traditions, which should lead to common definitions that acknowledge learning design both as a verb and a noun. Such dialogue would promote the establishment of common standards - not just in the technical sense (such as the existing IMS-LD specification), but in terms of scientific standards, best practices, and measures of quality.

Dobozy (2011, p. 9) highlights the challenges to Learning Design raised by TEL, quoting Slavin's (2008) claim that "education today is at much the same prescientific point as medicine was a hundred years ago", and argues that Learning Design holds a viable potential for addressing these challenges. Yet, she contends, this potential is undermined by competing traditions and terminologies and lack of clarity, as demonstrated by Berggren et al. (2005, p. 4):

The initial immersion into Learning Design gave us an experience of confusion over terms, concepts and tools. Our group constantly mixed discussions amongst conceptual points, codified specifications and multiple tools which are in various stages of development. Teachers will need to grasp these differences before a meaningful discussion can take place.

Dobozy notes that even the basic terms are contested - the field itself is called 'learning design' (Dalziel, 2006) 'instructional design' (Chu \& Kennedy, 2011) 'curriculum design' (Ferrell, 2011) 'educational design' (Goodyear \& Ellis, 2011), 'design for learning' (Beetham \& Sharpe, 2007), and 'design-based learning'(Wijen, 2000). While it is arguable that some of these are distinct perspectives, these distinctions need to be clarified and the synergies and overlaps among the traditions need to be explored. Cameron (2010) provides a concise review of the varying perspectives on "what is learning design". Building on this, Dobozy suggests a classification of three types of Learning Design: Type 1 'Learning Design as a concept', Type 2 'Learning Design as a process', and Type 3 'Learning Design as a product'. Her contention is that learning design workflow follows this conceptual structure, and that it is roughly sequential. Learning design must be conceptualised before it can followed as a process that leads to specific design outputs.

The lack of clarity highlighted by Berggren et al. and Dobozy is echoed by Goodyear and Dimitriadis'(2013) concern that the rapid technical and practical growth of the field is outpacing its theoretical development, running a risk of building high castles on slim foundations. We contend that this indicates that the field has reached a point where it needs to discuss its foundational frames, or what the educational design research community calls its commissive space and argumentative grammar (Cobb \& Gravemeijer, 2008; Kelly et al., 2008; Kelly, 2004): the substrate of rules and assumptions which bind the discourse of a community, and the logical system 
by which claims are presented and justified. We offer the above characterisation of learning design as a step in that direction.

The ASLD workshop addressed key contemporary research issues in Learning Design. The workshop was organised by the three major themes: Practices, Methods, and Methodologies (Dobozy's Type 2 and to some extent Type 1), Tools and Resources (Type 2 and Type 3), and Theories and Frameworks (Type 1). The most obvious difference is that Type 3 refers to designed artefacts for learning, such as models, templates, or lesson plans describing roles and resources needed for a specific learning activity. These artefacts per se were not one of the thematic strands, but are the final result of using the methods, tools, and resources of Learning Design. For example, one might use software such as LdShake (Hernández-Leo et al., this volume chapter 14) or ScenEdit (Emin et Pernin, this volume chapter 13) to generate a model for learning. The most clear example of a Type 3 artefact is described by Walmsley in Chapter 13. Notwithstanding these slight differences, we have loosely organised the book into similar conceptual groupings, though not preserving the same sequence.

\section{LEARNING DESIGN AND INSTRUCTIONAL DESIGN}

In considering the current research in Learning Design we must also address the significant body of work in the domain of Instructional Design (ID). The two share many broadly overlapping attributes, which can lead to some confusion among both researchers and practitioners. ${ }^{1}$ As chronicled by Reiser (2001), Instructional Design traces its origins to the Second World War and the need of the US military to rapidly train large numbers of people in performing technical tasks both for domestic production of war materiel and for combat. Learning Design is more often associated with the emergence of online and technology-enhanced learning research in the late 1990s and 2000s, though Instructional Design has embraced research in learning technologies and efficiencies in the production of adaptive teaching materials for considerably longer. But their differences stem from more than terminology or historical origin. Most notably perhaps, they have somewhat different theoretical backgrounds, with Instructional Design emerging from a behaviourist perspective, and Learning Design more from constructivist theory. This has led Instructional Design to focus on learning artefacts and methods, and in designing and delivering instruction according to instructional events and their relevance to specific psychomotor learning skills. A systematic approach to task decomposition and training characterised the early methods of Instructional Design, which were later modified with the arrival of systems engineering techniques from the domain of computing and research into cognitive load (e.g., Sweller, 1994).

By contrast, the relatively recent emergence of Learning Design research has seen more emphasis on the learner's context and in constructivist interpretations of the learning process, situated within an ecology of technological tools to support this. Perhaps due to its longer history, the use of Instructional Design has received 
greater attention in the US than elsewhere. MacLean and Scott (2001) also observe that the level of professional support and development for Instructional Design is more developed in the USA and Canada than in the UK. Another consequence of these different historical and theoretical perspectives is that there are both gaps and overlaps in the literatures, and the research within one community which might be particularly relevant to the other may go untapped or unnoticed. For example, acknowledgement of Instructional Design developments in the constructivist arena (Morales, 2010; Stone \& Goodyear, 1995; Willis, 1995, 2009). The bodies of research remain relatively siloed and cross-publication is infrequent. Rather than take sides, we feel that it is best to recognise the differing traditions and the useful research from both communities by incorporating it into our thinking about Learning Design. This conciliatory position is also adopted in Goddard, Griffiths, and Wang (this volume chapter 9). At the same time, our work has centred upon technologyenhanced approaches to the challenging task of supporting teaching and learning, and as this is the fount from which Learning Design has emerged, it seems a more suitable title for this collection.

\section{ISSUES AND GRAND CHALLENGES}

The work in this book is indicative of the growing discourse and the vibrant community of researchers and practitioners that are shaping the field. On one hand the field is maturing, with the articulation of theoretical and methodological frameworks, the availability of a wide choice of tools, and the build-up of a canon of literature. On the other hand, several challenges are emerging as clear directions for future work. We see three pivotal issues as being most crucial to its evolution. If the promise of Learning Design research is to employ technology to improve learning, it will do this by supporting teachers and by extension, learners, who are in the end, the focus of all our efforts! But it will not live up to its potential unless it can (i) authentically represent teachers' practice in a familiar parlance, (ii) can support practitioners with useful, open tools, and (iii) can support learning design as a design practice. These are three of the grand challenges arising from the research in this book.

The first challenge is the standardisation of a comprehensive representational infrastructure: human-readable, textual and graphical (and perhaps dynamic) forms of describing learning design at multiple levels of abstraction. One metaphor that surfaced repeatedly at the ASLD workshop was that of musical notation. This metaphor is also examined in length in the Larnaca Declaration (Dalziel et al, 2013 and Daziel, this volume chapter 1). Musical notation enables complex, expressive, dynamic, time-based content to be captured accurately and succinctly, yet expressively. Moreover, the symbolic, formalised abstraction of the content does not impede interpretation and reproduction. On the contrary, capturing the "essence" of a musical work formally facilitates the creative expression of the composer, whilst leaving room for interpretive reproduction of musicians. Take the genre of jazz, for 
example. The music of Miles Davis can be interpreted in myriad ways by many musicians, without losing its essential nature. Teachers have frequently related their desire to record the essence of their practice (at various levels of detail and with kinds of activities), whilst not sacrificing their ability to be creative, due to limitations of the means of capture. Yet if pushed too far, this analogy breaks down. In the end, one would like to be able to assert that a particular teaching method or approach leads to better learning experiences among students and some formative or summative assessment metric is inevitably involved in demonstrating this. Music, a largely aesthetic endeavour, is less germane to this kind of evaluation. However, the impact of notation on dissemination, sharing, and indeed creative expression of music would be hard to understate. Another useful analogy is the language of architectural drawings. Architects design process is scaffolded by a progression through a series of graphical and other articulations of their ideas. These representations afford a discussion of the design objectives and the means chosen to address them. They eventually require the interpretation of craftsmen in order to be implemented as physical buildings, yet any professional can assess whether a certain construction matches the design prescribed in the drawings. The field of Learning Design is rich in languages but lacks common agreement around basic terminology, although recently some specific attempts have been made (Reigelugh \& Carr Chelman, 2009). It enjoys an impressive array of textual, graphical and computational representations of practice and resources, yet it hasn't found the canonical "drawing" or "notation" that music and architecture have.

Once a consistent notation system is established, it can become: (1) a tool for remembering designs, (2) a structured problem-solving work space where designs can take form, and (3) a laboratory tool for sharpening and subdividing abstract design categories. Through a continuing cycle of refinement, both design language and notation system grow in parallel, and more sophisticated design ideas result" (Gibbons et al., 2008, p. 642).

In order for educators to effectively orchestrate learning within this landscape, they need to perceive themselves, and indeed to be perceived by society, as technopedagogical designers. A design attitude should be reflected in the production of new resources, as well as in effective configuration and customisation of existing ones. The design paradigm has established itself in TEL research. Yet, for it to attain its full desired impact, it needs to develop a common language and make this language accessible to the widest possible audience. Such a language, and the related media of interaction, should allow experts and novices to extract design knowledge from experience, articulate it in a coherent manner, connect, combine and manipulate it, and use it to resolve new challenges. These issues are the focus of the chapters in Section 1, and to some degree, in Section 2.

This leads us to the second challenge, which is the focus of Section 2: a common language of learning design needs to be supported by appropriate tools, resources and community spaces that will streamline the process of constructing, validating and using design knowledge, making it open, accessible and transparent. It cannot 
be a uniform, centralised entity, but must allow for a diversity of discourse by establishing a set of open protocols and standards over which large-scale open collaborative knowledge building can thrive. This process needs to be embedded in the culture of the professional community. Again, recent years have witnessed the flourishing of an impressive arsenal of learning design tools. Yet, no single tool can address the requirements of all practitioners in all situations. Nor can a single tool can provide a "round trip" solution, which must support the full cycle from inception, through challenge definition, conceptualisation, elaboration, enactment, evaluation and reflection, and back to remodelling. Thus, the question is: how do we create a platform for open, live, malleable, dynamic representations of design knowledge in TEL, supporting collaborative processes of design for learning, learning to design, and learning by design, and including the broadest community possible in these processes?

A common language of learning design and a comprehensive platform to support it are necessary but not sufficient conditions for the emergence of a professional culture of learning design. The design activity entails dealing with ill-defined problems subjected to evolving constraints. More specific guidance would benefit designers; particularly novice designers. Cross (2008) introduces the notion of 'methods' as more prescriptive and detailed descriptions of procedures (also present in literature as activities, tasks, techniques, etc.). The methods have two main features in common: they formalize certain procedures of design, and they externalize design thinking enabling the representation of solutions into concrete artifacts (drawings, charts, diagrams, etc.) of communicative and conversational power (Maina, 2012). As an example, see the COED method (Ryberg et al., this volume chapter 6).

An open platform for learning design might promote the emergence of a new culture of educational practice, in which expertise is rapidly and effectively shared, critiqued and aggregated. It will provide for the wide proliferation of cost-effective and robust educational practices, making effective use of technological advances as they appear. However, such a culture will not be instigated simply by the existence of the right tools and representations. The existing Learning Design community needs to engage in a massive project of professional development, driving a new perception of educational profession, as a rigorous creative practice of perpetual innovation. The principles underlying the Learning Design approach, the practices reifying those principles, and the methodological framework binding those together need to be made explicit and communicated to the widest audience possible.

Finally, Section 3 addresses the third challenge: the uncharted links and dimensions of a design approach to Learning Design practice need to be explored. Other design disciplines emphasise their creative and aesthetic qualities. How are these reflected in the domain of Learning Design? Should we promote them, and how? Can we evaluate the creative and aesthetic qualities of a particular learning design process or artefact? On the other hand, design approaches have recently gained prominence in educational research. Should we, and can we, forge links between design-based research and research-inspired practice? Several studies (Ronen-Fuhrmann, Kali 
\& Hoadley, 2008; Voogt et al., 2011) demonstrate the value of engaging in design for teachers' professional development. This is no surprise, if we acknowledge educators' continuous development as a learning process, and consider learningby-design as a powerful pedagogical framework. Mitch Resnick (2007) calls for reconceptualising education to promote the creative society. In order to do that, we need to reconceptualise teaching as a creative practice. With this in mind, we propose a view of learning design as a grounded, rigorous, and creative process of perpetual educational innovation: grounded in a well-defined concrete context of practice, rigorous in its attention to scientific evidence and pedagogical theory, and creative in its approach to generating new solutions to educational challenges.

\section{WHERE TO NEXT?}

Before we proceed to a brief outline of the chapters of this volume, we conclude the discussion with a view to the future. Where do we see the most promising developments on the horizon?

Currently we are witnessing a growing excitement about the potential of "big data" in education. The emerging field of learning analytics promises to revolutionise the way we learn and teach by offering real-time, personalised feedback and guidance based on the analysis of large quantities of data. Proponents refer to examples from e-commerce and e-health, as well as other fields (such as epidemiology) where analysts use large data sets and powerful computational tools to identify trends and population dynamics, use these to predict individual behaviour and respond to it in an effective manner. If Amazon can use "big data" to recommend your next purchase, why can't we use the same methods to recommend your next course? Imagine the potential of a personalised automated tutor, who has the insights of observing a million learners before you - and uses that to guide you on the most effective learning path.

Indeed, learning analytics is already showing impressive results. Yet it faces considerable challenges before it can fully realise its promise. Some of these challenges are technical - e.g. how do we share data and processing power across systems, to leverage synergies and economies of scale, without compromising system stability or user privacy? Some of these challenges are ethical: how do we avoid "machine determinism" where a learner's future is induced from the data of her past, and therefore "unrealistic" option are automatically closed to her. Yet other challenges are pragmatic: most learning is still situated out of reach of logging. Even in pure distance education scenarios, learners often conduct much of their activity outside the VLE - they will download or print materials to read offline, search for supplemental content on the web, or work out exercises with pen and paper. Such activities cannot be tracked, and therefore cannot be analysed. Apart from the obvious challenge, there is a risk that where we cannot measure what we ask, we will end up only asking what we can measure. Finally, there are conceptual challenges - which are perhaps the greatest challenges of all. Learning 
is a much more complex process than shopping. Many great thinkers, from Socrates to Piaget and Vygotsky, demonstrated how learners must pass through states of confusion, conflict and contradiction to achieve meaningful progress. In simple terms, you cannot learn before you acknowledge that there is a gap in your knowledge or skill - and that is often an unpleasant realisation. Yet such states will appear as black marks on an analytics graph - and an automated system would attempt to avoid them.

Apart from the technical challenges, these issues point to the critical role of the dialogue between learning analytics and learning design. On one hand, learning analytics can inform and validate learning design: identify the points where re-design is called for, and confirm the effectiveness of good designs. On the other hand, learning design can give substance to the "learning" in learning analytics: without a representation of the detailed educational objectives, and the expectations in terms of the learner activities which will promote them, learning analytics is reduced to monitoring generic behaviours - such as persistence and perseverance, or social interactions. Learning design can provide a rich description of learning experiences in terms of the expected practices and activities of learners, which can then be monitored by learning analytics. The synergy between Learning Design and Learning Analytics opens up new possibilities for both. For example, it creates the option of designing learning experiences which assume the availability of learning analytics and thus incorporate checkpoints for self-reflection using the analytics outputs.

There is a third vertex to this triangle: Teacher Inquiry. We discussed Schön's notion of design as practitioner inquiry. The emerging trend of teacher inquiry (Avramides et al., 2014; Makri et al., 2014) suggests a projection of this idea into educational practice. Teacher inquiry applies the ideas of inquiry-based learning to teachers' professional development. Teachers phrase conjectures about students' learning, and conduct classroom experiments to test these. Consequently, teachers enhance both their theoretical knowledge and their practical skills. The interleaving between Learning Design and Teacher Inquiry is aligned both with Schön's conception of design as inquiry and with Simon's model of design science. Learning analytics provide the instrument for making this design inquiry of learning truly powerful. The potential of this three-way synergy has been discussed by Emin-Martínez et al. (2014) and is the subject of a forthcoming special issue of the British Journal of Educational Technology (Mor, Ferguson \& Wasson, 2015).

On a more technical-pragmatic level, we see an important emerging trend in the development of integrative learning design environments. Persico et al. (2013) and Prieto et al. (2013) demonstrate the diversity of tools and representations already available in the field of Learning Design. This diversity highlights the richness of theoretical and practical approaches to the issues at hand. Yet, each one of these covers a particular phase of the learning design cycle, or embodies a specific practice. Again, the comparison to other design disciplines is helpful: an architect will often start her work with a crude sketch, using soft pencils and paper. She will then proceed through a series of ever-more-detailed and accurate representations, 
using progressively complex tools as she proceeds. Finally, a fully specified set of plans will be handed over to contractors for implementation. As the field of Learning Design matures, we need to move beyond the tensions between competing formats, and instead focus on open standards and platforms for seamless interchange from one format to the next. A promising step in this direction is the Integrated Learning Design Environment - ILDE (Hernández-Leo et al., 2014).

\section{CHAPTER OVERVIEW}

This book represents an effort to organise some of the contemporary research that is addressing these grand challenges of Learning Design. We have structured it according to the three major themes from the ASLD workshop from which the book has its origins whilst acknowledging Dobozy's useful conceptual Types. We turn now to a brief discussion of the chapters themselves and how they relate to this structure.

\section{Theories and Frameworks}

Theory generation can arise from both from findings of research aimed at theory building and from reflection upon practitioner experiences. Such theories can support the development conceptual frameworks to support the learning design process. In the opening section of this book, we explore some of the emergent theories and knowledge frameworks that are influencing the epistemology of Learning Design, and which address the aforementioned grand challenge of implementing a designbased approach and a culture of design practice. This is by no means a fully comprehensive picture. Rather, we aim to provide a sample of some of the current thinking in this area and which arose from the collective, collaborative experiences of participants at the ASLD 2011 workshop.

In the first chapter, Dalziel discusses the Larnaca Declaration, the work of a group of experts who met to review and reflect on the history and current state of the field. This is followed by Goodyear et al. who develop conclusions regarding the structure of networked learning environments and discuss the structural relationships between learning design patterns, and Alexandrian architectural patterns. As with Alexandrian patterns, learning design patterns have always been intended to bring learning design principles to a large audience of practitioners... Ronen-Fuhrmann and Kali address the deeply important issue of bringing theory to practice and supporting the very practitioners that researchers aim to help. They present a study of graduate students in Education - the very people who will put contemporary research in learning design into practice. They show how the students' use of an epistemological model to aid them in designing learning in TEL modules closes gaps between theoretical and applied knowledge. This work also informs the refinement of an innovative Design Principles Database 
which could be useful not only to students but to seasoned teachers. Finally, Pozzi, Persico and Earp conclude this section with an analysis that provides a multidimensional framework drawing together a number of representations for design of learning. Their analysis of the key dimensions characteirizing the existing representations for Learning Design, namely: format, level of formalism and level of contextualization, purpose, and types of end users, identifies essential areas for further investigation.

This conclusion to the thematic strand on Theories and Frameworks shines a light on the potential areas for fruitful continued research and development and provides an epistemological capstone to the thematic strands on Methods and Tools. We close the book with some reflections on these significant research opportunities and discuss the possible positive consequences for the future of Learning Design.

We believe that the bounty of enthusiastic research in Learning Design will continue to be fruitful for the key recipients of our industrious efforts: other researchers, teachers, and not least, learners. Indeed many of us within the research community have been or continue to be teachers and learners, ourselves. These communities come in many shapes and from diverse, rich traditions and cultures around the world. Yet, they face the common challenges of mutual collaboration, sharing, and support in the complex social and increasingly, socio-technical process that is 21 st Century learning. The work here is emblematic of the aspirations to meeting this challenge and confirms that we are heading in the right direction, together.

\section{Practices, Methods, and Methodologies}

In the second thematic section, we review some contemporary trends in the practices, methods, and methodologies of Learning Design, from identifying and rationalising the stages of the learning design process, to evaluating the results of design work done and interpreting what is and is not effective. Much of the literature in Learning Design describes the representations or the products of design work, but not the process itself. Thus, we begin with Mckenneys' chapter addressing the gap between TEL research and practice, and how their interplay informs education innovation. In another approach to e-Learning design, Ryberg, Buus, Georgsen, Nyvang, and Davidsen describe a method that emphasizes collaboration in the design process and illustrate how this can help creating Learning Designs based on activities, resources and infrastructure. Warburton and Mor address the recent interest in Design Patterns with a unique triad of activities to yield practitioner-generated learning designs. They provide substantive and documented practices leading to theoretical and procedural development in Learning Design. Masterman notes the importance of evidence in assessing the effectiveness of the design process, using a case study to describe a method of analysing learning design software. She highlights the important consequences for Learning Design more broadly. 
Concluding this thematic section, two chapters explore the importance of "getting it right" in Learning Design and explore how difficult it can be to achieve this, despite serious and well-placed efforts. The IMS-LD approach has attracted noteworthy attention within the Learning Design community and has gained a lot of support from researchers since its introduction in 2003. However, its uptake has remained relatively slow, given this level of interest. This raises interesting questions as to why progress has been so stunted. To address this, Goddard, Griffiths and Wang describe a study comprising interviews of practitioners and leading participants in the IMS-LD community which attempts to explain the limitations to its adoption. Fleshing out this picture from an applied perspective, in the concluding chapter of this thematic section, Burgos illustrates some of the practical challenges of implementing IMS-LD, providing evidence from several learning scenarios and a case study. The challenges to adoption of IMS-LD serve to illustrate both the importance and the difficulty of providing a unified foundation upon which to support learning designers and practitioners.

\section{Tools and Resources}

In addition to the difficulty of developing design practices and methods, an ancillary challenge is that there are few tools to support the learning design process itself. Many other design-focused disciplines have seen the emergence of significant software supports for their work. Architects and engineers have their CAD tools, Graphic Designers and 3D animators can choose from a range of creative suites, and there are even packages for designing performative activities such as theatrical lighting. Yet, to support the complex process of Learning Design, there are comparatively few tools to choose from. The third thematic section of this book explores some of the most recent and promising of them.

As research in Learning Design has matured, systematic approaches have led to the development of a modest number of software systems and platforms to support design activities. These implement methods of learning design at various levels of learning activity and support for sharing work with others. As a contrasting view on the challenges raised for IMS-LD in the previous thematic section, Derntl opens the third theme by describing another IMS-LD compliant system, OpenGLM, which supports the first two levels of IMS-LD design, but without the need to be an expert in the framework. It provides a set of visual representations and simple interactions to aid practitioners in designing and sharing IMS-LD based designs. Effective representations and ease-of-use are intimately intertwined. As noted extensively in Botturi and Stubbs (2007), significant challenges are raised by the difficulty of meaningfully expressing such representations. Brasher and Cross have created a tool for just this purpose, and in the subsequent chapter, reflect upon what they have learned in using and refining CompendiumLD. They show how the challenges of representation will likely become more acute as technology-supported learning designs become richer and more complex. 
Familiar representations are also important for giving teachers new ways to engage with technology to enhance learning design. In the next chapter, Walmsley illustrates this principle by presenting a simple pedagogic template in the form of a Word document. She shows how this can be extremely effective for creating curriculum and tool-focused e-Learning, at this micro-level of design work, where planning individual learning activities or sessions occurs. Learning design systems can equally operate at more strategic level to support thinking about both learning and the required resources to support it. An emphasis on sharing and co-edition are the basis for a case study in the use of LdShake, described by Hernández-Leo, et al. Their focus on social-network oriented work and sharing across teams and institutions also illustrates how innovations in learning design can affect larger initiatives across schools and communities. Rounding out this panoply of software, Emin and Pernin describe both a conceptual framework for learning design and a tool, ScenEdit, which implements it. Their work straddles two thematic stands of this book, but we situate it among the other tools to highlight how tight integration of a theory-driven conceptual framework (ISiS), can be effectively manifested in software.

\section{NOTE}

1 For an interesting overview of the lively discussions surrounding this, see 'Learning Design vs. Instructional Design', a Cloudworks discussion thread at http://cloudworks.ac.uk/cloud/view/2536. Last accessed: 26 Nov 2014.

\section{REFERENCES}

Avramides, K., Hunter, J., Oliver, M., \& Luckin, R. (2014). A method for teacher inquiry in cross-curricular projects: Lessons from a case study. British Journal of Educational Technology, 46, 249-264.

Beetham, H., \& Sharpe, R. (2007). Rethinking pedagogy for a digital age. New York, NY: Routledge.

Beetham, H., \& Sharpe, R. (2013). Rethinking pedagogy for a digital age: Designing for 21st century learning. London: Routledge.

Berggren, A., Burgos, D., Fontana, J., Hinkelman, D., Hung, V., Hursh, A., \& Tielemans, G. (2005). Practical and pedagogical issues for teacher adoption of IMS learning design standards in moodle LMS. Journal of Interactive Media in Education, 2. Retrieved from http://jime.open.ac.uk/2005/02/

Botturi, L., \& Stubbs, S. T. (2008). Handbook of visual languages for instructional design. Theories and practices. Hershey, PA: Information Science Reference.

Buck, G. H. (1989). Teaching machines and teaching aids in the ancient world. McGill Journal of Education / Revue des sciences de l'éducation de McGill, 24(1), 31-54. Retrieved from http://mje.mcgill.ca/article/view/7845/5774

Cameron, L. (2010). How learning design can illuminate teaching practice. In proceedings of the future of Learning Design Conference (pp. 20-27). Australia: University of Wollongong. Retrieved from http://ro.uow.edu.au/fld/09/Program/3/

Chu, S., \& Kennedy, D. (2011). Using online collaborative tools for groups to co-construct knowledge. Online Information Review, 35(4), 581-597.

Conole, G. (2013). Designing for learning in an open world. New York, NY: Springer.

Cross, N. (2001). Designerly ways of knowing: Design discipline versus design science. Design issues, 17, 49-55. 


\section{Y. MOR ET AL.}

Dalziel, J. R. (2006). Lessons from LAMS for IMS learning design. In Proceedings of the Sixth International Conference on Advanced Learning Technologies (pp. 1101-1102) IEEE. doi:10.1109/ ICALT.2006.220

Dalziel, J., Conole, G., Wills, S., Walker, S., Bennett, S., Dobozy, E., ... Bower, M. (2013). The larnaca declaration on learning design - 2013. Retrieved December 17, 2014 from http://www.larnacadeclaration.org/

Dodd, B., Sime, M., \& Kay, H. (1968). Teaching machines and programmed instruction. New York, NY: Penguin.

Dobozy, E. (2011). Typologies of learning design and the introduction of a "LD-Type 2" case example. eLearning Papers, 27, 3-11. Retrieved from http://elearningeuropa.info/sites/default/files/asset/ In-depth_27_1.pdf

Emin-Martínez, V., Hansen, C., Rodríguez-Triana, M. J., Wasson, B., Mor, Y., Dascalu, M., ... Pernin, J. P. (2014). Towards teacher-led design inquiry of learning. eLearning Papers, 36(1).

Ertmer, P. A., Parisio, M. L., \& Wardak, D. (2013). The practice of educational / Instructional design. In R. Luckin, P. Goodyear, B. Grabowski, S. Puntambekar, N. Winters, \& J. Underwood (Eds.), Handbook of design in educational technology (pp. 5-19). New York, NY: Routledge.

Falconer, I., Finlay, J., \& Fincher, S. (2011). 'Representing practice: Practice models, patterns, bundles...' Learning, Media and Technology, 36(2), 101-127. doi: 10.1080/17439884.2011.553620

Ferrell, G. (2011). Transforming curriculum design - transforming institutions. Bristol, England, UK: Joint Information Systems Committee (JISC). Retrieved from http://www.jisc.ac.uk/publications/ briefingpapers/2011/bpcurriculumdesign.aspx

Gibbons, A. S., Botturi, L., Boot, E., \& Nelson, J. (2008). Design languages. In J. Spector, M. Merrill, J. Van Merrienboer, \& M. Driscoll (Eds.), Handbook of research for educational communications and technology (3rd. ed., pp. 633-645). New York, NY - London: Lawrence Erlbaum Associates.

Goodyear, P., \& Dimitriadis, Y. (2013). In medias res: Reframing design for learning. Research in Learning Technology, 21. doi: 10.3402/rlt.v21i0.19909

Goodyear, P., \& Ellis, R. (2007). Students' interpretations of learning tasks: Implications for educational design. In R. J. Atkinson, C. McBeath, S. K. A. Soong, \& C. Cheers (Eds.), Proceedings of the ASCILITE 2007 conference (pp. 339-346). Singapore. Retrieved from http://www.ascilite.org.au/ conferences/singapore07/procs/goodyear.pdf

Gravemeijer, K., \& Cobb, P. (2006). Design research from a learning design perspective. In J. V. den Akker, K. Gravemeijer, S. McKenney, \& N. Nieveen, Educational design research (pp. 17-51). New York, NY: Routledge.

Hernández-Leo, D., Asensio-Pérez, J. I., Derntl, M., Prieto, L. P., \& Chacón, J. (2014). ILDE: Community environment for conceptualizing, authoring and deploying learning activities. Proceedings of 9 th European Conference on Technology Enhanced Learning (pp. 490-493), EC-TEL 2014, Graz, Austria.

Holmberg, J. (2014). Studying the process of educational design - revisiting Schön and making a case for reflective design-based research on teachers 'conversations with situations'. Technology, Pedagogy and Education, 23(3), 1-18.

Kelly, A. (2004). Design Research in Education: Yes, but is it Methodological? Journal of the Learning Sciences, 13(1), 115-128.

Kelly, A. E., Baek, J. Y., Lesh, R. A., \& Bannan-Ritland, B. (2008). Enabling Innovations in Education and Systemizing their Impact. In A. E. Kelly, R. A. Lesh, \& J. Y. Baek, Handbook of design research methods in education (pp. 3-18). New York, NY: Routledge.

King, A. (1993). From sage on the stage to guide on the side. College teaching, 41(1), 30-35.

Koper, R. (2006). Current research in learning design. Educational Technology \& Society, 9 (1), 13-22.

Latour, B. (2008). A cautious prometheus? A few steps toward a philosophy of design (with Special Attention to Peter Sloterdijk). In J. G. Fiona Hackne \& V. Minto (Eds.), Proceedings of the 2008 Annual International Conference of the Design History Society (p./pp. 2-10). Florida, US: Universal Publishers.

Laurillard, D. (2008). Technology enhanced learning as a tool for pedagogical i nnovation. Journal of Philosophy of Education, 42, 521-533. 
Laurillard, D. (2013). Teaching as a design science: Building pedagogical patterns for learning and technology. New York, NY: Routledge.

Maina, M. (2012). Developing a method for the design of sharable pedagogical scenarios. In N. Alias, \& S. Hashim (Eds.), Instructional technology research, design and development: Lessons from the field (pp. 86-101). Hershey, PA: Information Science Reference. doi:10.4018/978-1-61350-198-6.ch006

Makri, K., Papanikolaou, K., Tsakiri, A., \& Karkanis, S. (2014). Blending the community of inquiry framework with learning by design: Towards a synthesis for blended learning in teacher training. The Electronic Journal of e-Learning , 12(2), 183-078.

Mor, Y., \& Craft, B. (2012). Learning design: Mapping the landscape. Research in Learning Technology, 20.

Mor, Y., Craft, B., \& Hernández-Leo, D. (2013). Editorial: The art and science of learning design. Research in Learning Technology, 21.

Mor, Y., Ferguson, R., \& Wasson, B. (2015). Editorial: Learning design, teacher inquiry into student learning and learning analytics: A call for action. British Journal of Educational Technology, 46, 221-229. doi: 10.1111/bjet.12273

Morales, C. R. (2010). Constructivist instructional design: A blueprint for online course design. In H. Song \& T. Kidd (Eds.), Handbook of research on human performance and instructional technology (pp. 24-42). Hershey, PA: Information Science Reference. doi:10.4018/978-1-60566-782-9.ch002

Persico, D., Pozzi, F., Anastopoulou, S., Conole, G., Craft, B., Dimitriadis, Y., Hernández-Leo, D., Kali, Y., Mor, Y., Pérez-Sanagustín, M., \& Walmsley, H. (2013). Learning design rashomon I Supporting the design of one lesson through different approaches. Research in Learning Technology, 21.

Prieto, L. P., Dimitriadis, Y., Craft, B., Derntl, M., Émin, V., Katsamani, M.,... Villasclaras, E. (2013). Learning design rashomon II - exploring one lesson through multiple tools. Research in Learning Technology, 21.

Reigeluth, C. M., \& Carr-Chellman, A. A. (2009). Understanding instructional theory. In C. M. Reigeluth \& A. A. Carr-Chellman (Eds.), Instructional-design theories and models, volume III: Building a common knowledge base (pp. 3-26). New York, NY: Routledge.

Reiser, R. (2001).A history of instructional design and technology: Part II: A history of instructional design. Educational Technology Research and Development, 49(2), 57-67. doi:10.1007/BF02504928

Resnick, M. (2007). Sowing the seeds for a more creative society. Learning and Leading with Technology, $35(4), 18-22$.

Schön, D. A. (1992). Designing as reflective conversation with the materials of a design situation. Knowledge-Based Systems, 5, 3-14

Slavin, R. E. (2002). Evidence-based education policies: Transforming educational practice and research. Educational Researcher, 31(7) , 15-21. doi: 10.3102/0013189X031007015

Slavin, R. E. (2008). Evidence-based reform in education: What will it take? European Educational Research Journal, 7(1), 124-128. doi:10.2304/eerj.2008.7.1.124 Hoboken, NJ: Wiley.

Stone, C., \& Goodyear, P. (1995). Constructivism and instructional design: Epistemology and the construction of meaning. Originally published in Spanish (in 1995) as "Constructivismo y diseño instruccional: Epistemology construccion del significado". Substratum: Temas Fundamentales en Psicologia y Educacion, 2(6), 55-76.

Sweller, J. (1994). Cognitive load theory, learning difficulty, and instructional design. Learning and Instruction, 4(4), 295-312. doi: 10.1016/0959-4752(94)90003-5

Voogt, J., Westbroek, H., Handelzalts, A., Walraven, A., McKenney, S., Pieters, J., \& de Vries, B. (2011). Teacher learning in collaborative curriculum design. Teaching and Teacher Education, 27(8), 1235 1244. doi: 10.1016/j.tate.2011.07.003

Wijen, W. (2000). Towards design-based learning. OGO brochure, No 2. Educational Service Centre. Eindhoven, NL: Technische Universiteit. Retrieved from http://w3.tue.nl/fileadmin/stu/stu_oo/doc/ OGO_brochure_1_EN.pdf

Willis, J. (1995). A recursive, reflective instructional design model based on constructivist-interpretivist theory. Educational Technology, 35(6), 5-23.

Willis, J. (2009). Constructivist instructional design (C-ID): Foundations, models, and examples. USA: Information Age Publishing. 
Y. MOR ET AL.

Yishay Mor

Institute of Educational Technology

Open University, $U K$

\section{Brock Craft}

Institute of Education, London Knowledge Lab

Goldsmiths, University of London, UK

Marcelo Maina

Psychology and Education Department

Universitat Oberta de Catalunya, Barcelona 
SECTION 1

THEORIES 



\title{
1. REFLECTIONS ON THE ART AND SCIENCE OF LEARNING DESIGN AND THE LARNACA DECLARATION
}

\begin{abstract}
INTRODUCTION
The Larnaca Declaration on Learning Design (Dalziel et al., 2013) provides a new synthesis of key concepts in the field of Learning Design, arising from a meeting of experts originally held in Larnaca, Cyprus in September 2012. This meeting grew out of several prior meetings supported by an Australian Learning and Teaching Council National Teaching Fellowship to the author (2011-2013), and "pedagogic planner" meetings in earlier years co-hosted by the author and Diana Laurillard.

These meetings had struggled to find a way to describe the conceptual foundations of Learning Design - in particular: the core concept of a "neutral" descriptive framework for many different kinds of teaching and learning activities; the wider context for teacher-led designing of activities in education; and the role of theory and practice in achieving effective learning outcomes for students.

This chapter provides an overview of the Larnaca Declaration, followed by reflections on the role of "art" and "science" in learning design processes, viewed through the lens of the Larnaca Declaration.
\end{abstract}

\section{THE LARNACA DECLARATION ON LEARNING DESIGN}

Today's learners, educators, institutions and governments face complex challenges, especially regarding $21^{\text {st }}$ Century Skills/Graduate Attributes, and the appropriate use of technology. Learning Design, as a domain of inquiry and as a field of practice, aims to help these stakeholders devise effective responses to today's challenges. The Larnaca Declaration discusses the relevance of Learning Design for all disciplines and all levels of education (school, university, vocational and professional training) while acknowledging that the primary areas of interest to date have been schools and universities.

One of the core tenets of Learning Design is the concept of a descriptive framework for teaching and learning activities. The analogy of musical notation is helpful in understanding this concept, and the Larnaca Declaration uses this analogy extensively. After noting that in the past some argued that music notation was impossible, because music was too "ethereal": 


\section{J. DALZIEL}

... over many years the Western music tradition slowly developed a notational system for describing and sharing musical ideas. This standard format allowed great musical ideas to be shared from one musician to another without a need for personal contact.

... Music notation does not capture everything about musical ideas - there remains a significant role for performers to bring their own interpretations to music. But musical notation contains enough information to convey musical ideas from one person to another over time and space.

Music notation does not guarantee beautiful music - indeed, mediocre music can be written down just as precisely as beautiful music. Music notation allows for many different styles of music to be described using a single notational framework (p. 2, Larnaca Declaration).

These ideas are then applied to "educational notation" (ie, Learning Design) - the concept of describing the structure and flow of activities that educators and learners perform in classrooms and in online environments.

Just as Western music notation provides a framework for describing many different styles of music (eg, Baroque, Classical, Romantic, etc), as well as beautiful and mediocre examples within each of these styles; so too a unified descriptive framework for teaching and learning could describe many different pedagogical approaches (instructivist, constructivist, cognitive, etc) and more and less effective examples of these approaches.

Such a framework need not describe everything about the educational experience; rather, it would seek to provide enough information in order to allow one educator to replicate the effective teaching and learning ideas of another educator. This focus gives primacy to the idea of sharing teaching and learning ideas, which has been central to the field of Learning Design (eg, Conole, 2013), and technologies to support sharing (eg, LAMS Community, Cloudworks - see Conole \& Culver, 2010).

However, there is an important difference between a typical musical performance and a classroom experience is that music is usually reproduced "as is", whereas many educators would adapt and change any shared idea to best suit their learners. This phenomenon finds a parallel with music like Jazz, where improvisation and adaptation is part of the musical experience, even though the outcome could still be notated.

Finally, $21^{\text {st }}$ Century Skills/Graduate Attributes and other educational reforms often expect educators to use new teaching approaches, such as Problem-Based Learning, Role Plays, etc. Learning Design can encourage the adoption of new teaching approaches by making explicit the step-by-step process of these teaching approaches, and fostering the sharing of these processes using a common descriptive framework. It notes that wider sharing of effective teaching practices has not only pedagogical benefits (through improved student learning outcomes), but also productivity benefits (through decreased educator preparation time, arising from 
re-using effective ideas from other educators). The potential of sharing educational design knowledge is illustrated by two chapters in this volume: Ryberg et al., Chapter 6, and Hernández-Leo et al., Chapter 14.

\section{Learning Design Timeline and Example}

The origins of the field of Learning Design can be summarised based on four foundational projects:

the work of Koper and colleagues on EML (Koper, 2001) and its input into the IMS Learning Design specification (IMS GLC, 2003); the work of Laurillard, Conole, Beetham and many others in the UK in the early 2000s, such as the SoURCE project (Laurillard \& McAndrew, 2002); the Australian Universities Teaching Committee's Learning Design project, led by Ron Oliver, Barry Harper, John Hedberg and Sandra Wills; andthe Learning Activity Management System (LAMS) project led by the author.

For a timeline of subsequent developments in the field of Learning Design, covering many different communities, projects, tools and publications see the Larnaca Declaration (p. 7) or http://learningdesigntimeline.wordpress.com/ (note that the timeline, while broad-ranging, is not comprehensive).

To provide a more concrete example of a particular learning design for discussion, the Larnaca Declaration uses an example of a Role Play, and its representation in the LAMS software (see Figure 1). It notes that the example conveys information at three levels: an overall visualisation of the whole teaching and learning process; specific information about each individual task (such as the text of a question or a discussion topic, or a digital resources to view such as a video, etc); and a set of embedded XML instructions (not seen by the educator) to tell a Learning Design software system how to enact the overall flow of activities with the specific information required for each activity. Note that only the first of these three levels is visible in Figure 1. Other learning design examples included in the Larnaca Declaration including the AUTC Project "flow" diagram (AUTC, 2002), education patterns (Hernandez-Leo et al., 2006) and other course representations. Other chapters in this volume discuss additional tools and representations, such as CompendiumLD (Brasher \& Cross, this volume Chapter 11), OpenGLM (Derntl, this volume Chapter 12), ScenEdit (Emin et Pernin, this volume Chapter 13), while Pozzi, Persico and Earp (this volume Chapter 4) propose an approach to mapping different representations.

A key point arising from these examples is that unlike Western music notation, Learning Design is yet to develop a comprehensive and broadly agreed framework for describing teaching and learning activities, and hence each example given is a kind of "proto-Learning Design descriptive framework" - that is, a "taste" of a possible future comprehensive descriptive framework, each with different emphases. 


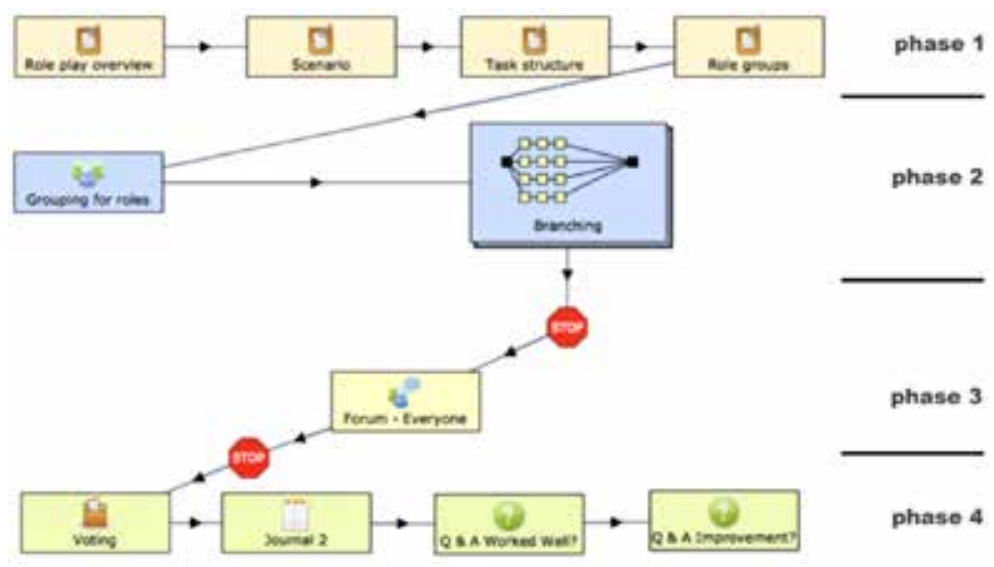

Figure 1. LAMS Authoring view of Role Play, with phases added (right side)

\section{Definitional and Conceptual Issues in Learning Design}

Definitional issues have been a significant challenge in the field, particularly for the phrase "Learning Design". The Larnaca Declaration proposes a number of clarifying phrases (listed in the Appendix) to aid discussion:

Learning Design (capitalised): The field of Learning Design a learning design (uncapitalised): An individual example of a sequence of teaching and learning activities, also called a "design" or "sequence". A learning design is a plan for potential activities with learners, which is to be distinguished from a particular implementation of this plan with a particular group of learners (see "a running learning design") a running learning design: The implementation of a learning design with a particular group of learners, also called "a running sequence".

IMS Learning Design: An example of a technical language for implementing the concepts of Learning Design in softwareteaching strategy: An approach to teaching that proposes a particular sequence of teaching and learning activities based on certain pedagogical assumptions... for example, Problem Based Learning, Predict - Observe - Explain, Role Plays and WebQuests. A teaching strategy can provide a pedagogical rationale as well as a suggested structure of activities for a learning design. (pp. 35-36, Larnaca Declaration)

For further discussion of IMS Learning Design see the chapters in this volume by Burgos (this volume Chapter 10), and Goddard, Griffiths and Wang (this volume Chapter 9). Beyond these clarifications, there is a deeper conceptual challenge in the idea of the "pedagogic neutrality" of a descriptive framework for Learning Design. Although no descriptive framework can be totally neutral, it can nonetheless aspire to being as neutral as possible - that is, an ideal Learning Design descriptive 
framework is able to describe many different pedagogical approaches within a single representational approach (just as music notation can represent many different styles of music).

\section{Learning Design Conceptual Map}

One of the major new elements of the Larnaca Declaration for the field of Learning Design is the "Learning Design Conceptual Map". This arose from discussion in Larnaca of the need for a wider view of the educational context in which Learning Design occurs, and the wide range of factors that affect design decisions. The Map seeks to reuse the idea of "neutrality" by incorporating a diverse range of elements that can affect design decisions, but without trying to specify a particular pedagogical theory about how they should interact.

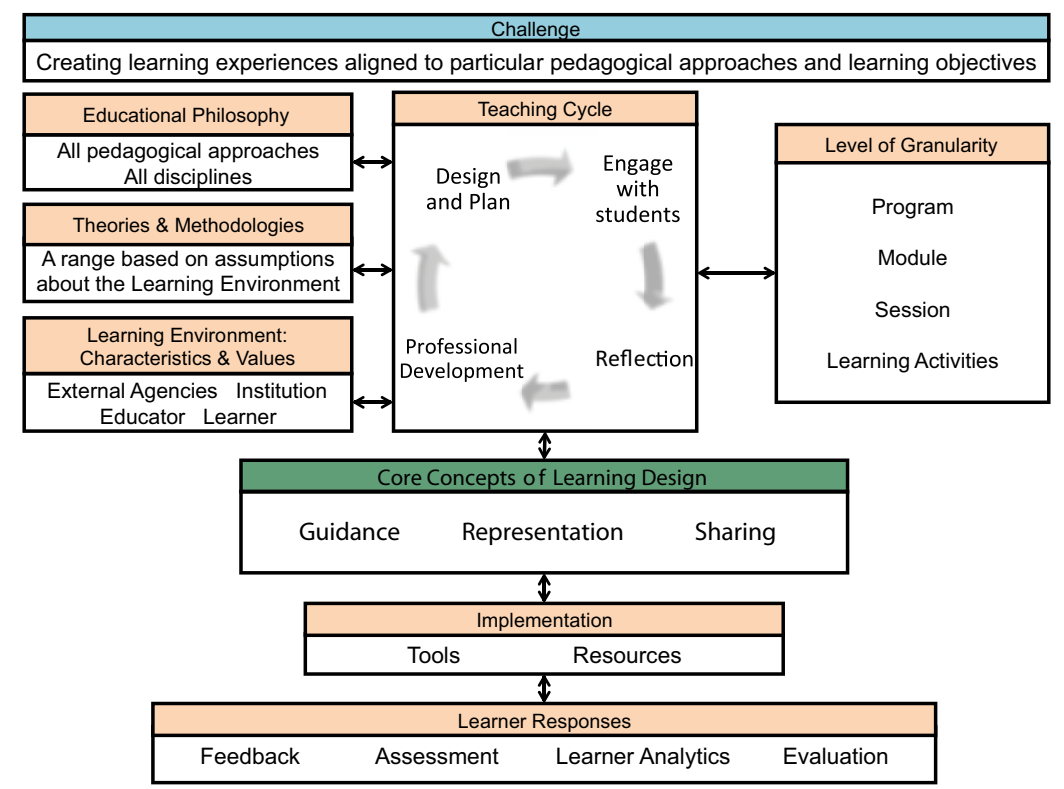

Figure 2. A Learning Design Conceptual Map (p. 14, Larnaca Declaration)

The Map notes the core concepts of Learning Design as representation and sharing, as well as guidance - that is, advice to educators on how to implement (and adapt) a particular learning design. Above this is an acknowledgement of the cycle that educators go through in teaching ("Teaching Cycle"), both in the immediate context of planning and implementing a class, as well as longer-term processes of reflection and professional development. These design processes are themselves affected by wider contextual factors, such as educational philosophy and metholodogies, and the characteristics and values of educators and learners, as well as institutions and 
external agencies. From a different perspective, the design process is also affected by the level of granularity in design - whether this is at the level of individual learning activities within a class, or the sequence of activities over a whole class or session, as well as wider "curriculum design" issues in the planning of whole modules, and whole degree programs.

In terms of implementation, the Map acknowledges the role of Learning Design tools and other resources (whether digital or physical) in implementing a particular learning design, and finally the key role of learner responses, including feedback such as immediate reactions, assessment performance, student evaluation of courses, and, where digital data are available, the potential for analytics arising from rich records of student activity (which can be captured by some Learning Design systems).

The Larnaca Declaration provides detailed discussion of each element of the Map, and how it relates to the "micro" task of designing and implementing particular learning designs, as well as the "macro" task of how an educator goes about educational design in the general. It also gives examples of how the Map can be used to analyse particular pedagogical theories: how each theory emphasises certain elements of the Map more than others, and how comparing two different pedagogical theories, as overlayed on the Map, illustrates their areas of common interest and their differences.

\section{Learning Design, Pedagogical Theories and Effectiveness}

Having laid the foundations described above, it is possible to consider again the thorny question of effective teaching and learning in Learning Design, and the role of pedagogical theories such as Instructivism, Constructivism, etc. Simply "notating" a teaching and learning experience is no indicator of its effectiveness (just as a beautiful or mediocre piece of music can equally be notated using the same music notation framework).

The Learning Design Conceptual Map provides a way of examining whether a particular learning design is well aligned to its wider context, and the importance of appropriate alignment of individual activities with wider requirements, assessment, etc.

Following from this, different pedagogical approaches can be better suited to particular contexts - that is, different topics, different types of students, different levels of education, etc. Educators make regular judgements about which teaching approaches are most effective for their particular groups of students, and these decisions are informed by professional practice, as well as broader assessment of learners, and by educational research.

The Larnaca Declaration argues that while all learning ideally seeks to be student-centric, in the sense of ultimately focussing on effective learning outcome for students, this does not mean that all teaching and learning activities need to be student-directed - indeed, lecturing and direct instruction may be the most effective learning methods for certain contexts. This argues for a plurality of teaching and 
learning methods driven by their effectiveness in achieving appropriate student learning outcomes, and the central role of the educator in making judgements about effective methods, drawing on the wide range of potential teaching and learning methods that can be described and shared using a Learning Design framework (for further exploration of the effectiveness of Learning Design tools in supporting teaching practices, see Masterman (this volume Chapter 8).

This approach suggests that the field of Learning Design involves three related but distinct concepts - the idea of a "neutral" descriptive framework, the wider conceptual map, and a third concept for describing the practice of designing and implementing effective teaching and learning (drawing on the discussion above). These three concepts are described in Figure 3.

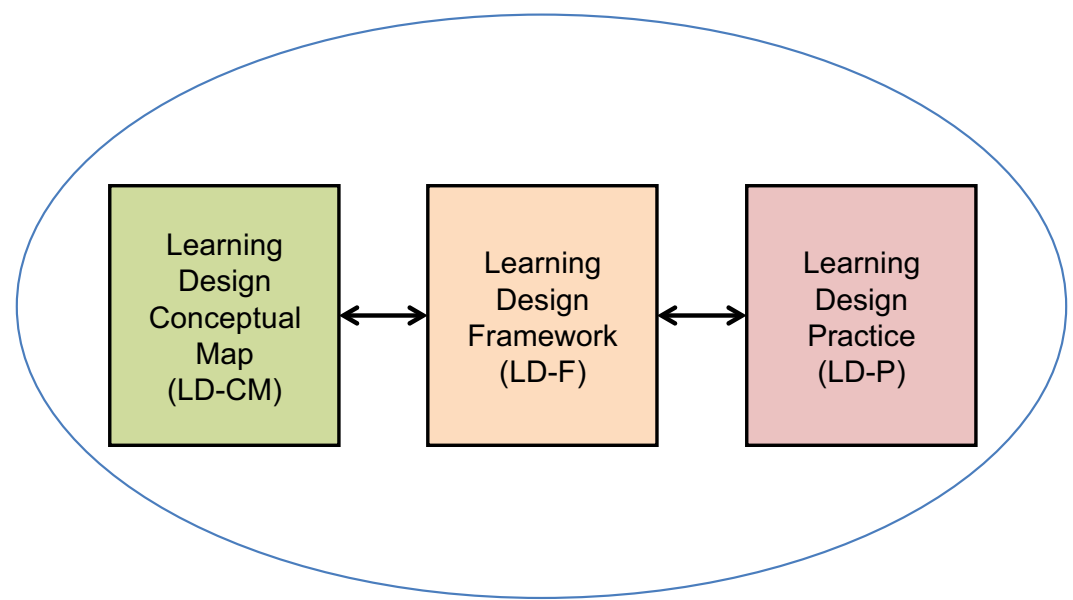

Figure 3. Components of the field of Learning Design (p. 32, Larnaca Declaration)

The Larnaca Declaration concludes with reflections on the potential limitations of the field, particularly the question of whether a broad, widely agreed descriptive framework is possible. It suggests that even if this goal proves unrealisable, the quest itself should teach us important lessons about the unique nature of education and the limits of attempting standardised descriptions of teaching and learning.

A seven point summary of Learning Design from the perspective of the Larnaca Declaration is:

- Representing learning designs in formal ways (LD-F)

- Sharing and re-using learning designs

- Encouraging localisation of learning designs for the needs of learners, and adaptation to different disciplines

- Focusing on pedagogy in all its forms across all sectors and disciplines (LD-CM)

- Applying the teaching cycle to implementing and improving learning designs 


\section{J. DALZIEL}

- Emphasising how learners learn, and hence how educators can teach effectively (LD-P)

- Building software to implement and share learning designs (p. 35, Larnaca Declaration)

\section{THE SCIENCE OF LEARNING DESIGN}

From the perspective outlined above, there are a number of reflections that can be offered on the "art and science" of Learning Design. In terms of "science", the work of educational research on investigating effective and ineffective teaching methods is particularly important to Learning Design - Practice (LD-P). The many findings of the fields of instructional design, learning science, educational psychology and neuroscience all have implications for how educators make choices about the most effective practices for their context. The synergies between Learning Design and Educational Design Research are explored in this volume by Ronen-Fuhrmann and Kali (this volume Chapter 3) and by McKenney (this volume Chapter 5).

Going further, Learning Design offers a more precise way to specify the steps taken in a sequence of teaching and learning activities, and this may allow for more precise comparisons of teaching methods during educational research (Dalziel, 2009). A careful ex post facto notation of the individual steps in two different teaching scenarios may help to identify the particular reason(s) for differences in outcomes, and subsequent confirmatory research can use a Learning Design descriptive framework to carefully describe the planned similarities and differences between an experimental group and a control group. This indicates how a Learning Design Framework (LD-F) could improve the quality of educational research through greater precision in comparisons. Goodeyear et al. (this volume Chapter 2) in this volume provide a vivid example of how Learning Design representations can support structural analysis of educational practices, which engender new theoretical insights.

From a different perspective, the science of structure and representation may be relevant to formulating Learning Design Frameworks. Unlike empirically driven research (such as education, chemistry, etc), the science of mathematics is, in a sense, the science of structure. The related fields of logic and computer programming also face the challenge of effective methods of representation for abstract concepts and structures. There may be valuable lessons to be learned from these sciences to inform the further development of a broad Learning Design Framework.

For example, in the Unified Modelling Language (UML - see Fowler, 2004), a key concept of representing software is that more than one representation/visualisation is required (given the complexity of software) and that each kind of representation conveys different types of information about a given example of software. It is possible that a future broad Learning Design Framework will not be just a "single" representation/visualisation (like music notation), but rather a group of different 
representations/visualisation, due to the complexity of describing teaching and learning processes (like UML).

\section{THE ART OF LEARNING DESIGN}

The rise of Learning Design has been, in some ways, a challenge to the concept of educational design as only "art" - as it tries to make explicit and shareable the design decisions of educators which in the past have usually been implicit. At times there has been an unfortunate tension between implicit art and explicit description in education, whereas a different way to approach the issue is to see the increasingly explicit description of education as a way of assisting educators to become more conscious of their often "pre-conscious" design processes, and based on this, to be able to add more "art" on top of their increasingly explicit underlying decisions.

This is particularly important for the issue of teaching "in the moment" - the decisions that educators makes in real-time as they watch their classes closely (in face to face environments), and how they adapt their teaching in response to their students' responses (see "Engage with learners" in the Teaching Cycle and "Feedback" in Learner Responses in the Learning Design Conceptual Map - LD$\mathrm{CM})$. As this aspect of education has to date been relatively weak in Learning Design, some educators have initially responded quite poorly to the ideas of Learning Design, as they feel this element of "live adaptation" is so central to their self-image as teachers that any approach that appears to give it less emphasis is undesirable.

In the context of the current discussion, it provides an excellent example of how the "art" of teaching remains an important part of the overall challenge of education, and hence of Learning Design as a whole. In the Larnaca Declaration this challenge is noted, and a comparison with the "improvisation" of Jazz is offered as a musical analogue to consider. Nonetheless, there are important aspects of effective teaching and learning that rely on the "real-time" attention and flexibility of educators, and this deserves further research and explication within Learning Design theory.

A second example of art in Learning Design is the sense that, when designing a set of teaching and learning activities, sometimes a particular choice "just feels right". This is most common for educators with significant experience in teaching their discipline and the typical challenges faced by learners. In terms of sharing, when an experienced educator hears of a teaching idea from a colleague in the same discipline, he or she may immediately sense its appropriateness ("it just feels right"), and hence seek to incorporate it into his or her own teaching. As noted elsewhere, even when educators do not directly re-use or adapt a particular learning design they have seen elsewhere, they may still be inspired by the essence of a learning design, and hence when they next design a set of activities "from scratch", they may nonetheless use the idea as inspiration for their new design (Dalziel \& Dalziel, 2011). 


\section{THE ART AND SCIENCE OF LEARNING DESIGN}

Going further, the sense that a teaching and learning idea "just feels right" can be seen as a combination of both the art and science of Learning Design. The "just right feeling" will typically arise from an intuitive grasp of the challenges of teaching a particular topic and the genuine needs of learners in this area. Even when this intuition is hard to verbalise, it can nonetheless be based on personal "empirical" experiences of effective teaching and learning in this context. Hence, an educator's intuitive sense of the appropriateness of a new idea, which may feel like the "art" of Learning Design, may in fact be based on accurate perceptions of the challenges of teaching in this context.

However, educators' impressions of effectiveness are not infallible, and hence a further benefit of the "science" of Learning Design is the potential for careful educational research on ideas that feel "just right", in order to determine whether their actual impact on student learning is effective in the way that an educator assumes. In other words, there is an interplay of both art and science in Learning Design, both in the "moment" of design, and in subsequent evaluation of the effectiveness of any given design.

As Learning Design becomes more mature as a field, and develops a more widely adopted descriptive framework(s), more "teaching strategies" (see definitions above) will be documented using Learning Design and hence more widely shared, and this, in turn, will provide more precise foundations for careful educational research to determine the effectiveness of different teaching strategies in different contexts.

\section{CONCLUSION}

The Larnaca Declaration provides a new way to integrate core concepts in the field of Learning Design, particular the concept of a descriptive framework (LD-F), the wider educational context that affects Learning Design decision (LD-CM), and the practice of designing effective teaching and learning experiences (LD-P). The music notation metaphor provides a useful way of thinking about how Learning Design seeks to describe (and share) examples of teaching and learning that can instantiate many different pedagogical theories. The music notation metaphor also offers an analogy for thinking about the effectiveness (or otherwise) of particular learning designs for learners that have been described and shared using a broad Learning Design Framework. Both the art and science of Learning Design are important to the Larnaca Declaration approach, particularly issues such as: moving from implicit to explicit descriptions of teaching; "improvisation" in teaching; the possibilities for representation; and the interplay between Learning Design and educational research. Teaching will continue to be a challenging "art", but it can be enhanced by the "science" of careful description of effective teaching and learning ideas, and by "artful" sharing and adaptation. 


\section{ACKNOWLEDGEMENTS}

Support for this publication has been provided by the Australian Government Office for Learning and Teaching. The views expressed in this publication do not necessarily reflect the views of the Australian Government Office for Learning and Teaching.

The Larnaca Declaration was based on ideas arising from a meeting of Learning Design experts in Larnaca, Cyprus on Tuesday $25^{\text {th }}$ September 2012 and subsequent discussions (hence the name "Larnaca Declaration on Learning Design"). The authors of the Larnaca Declaration are James Dalziel, Grainne Conole, Sandra Wills, Simon Walker, Sue Bennett, Eva Dobozy, Leanne Cameron, Emil Badilescu-Buga and Matt Bower.

Before and after the Larnaca meeting, a number of other meetings discussed similar issues, and these discussions contributed to the Larnaca Declaration. Participants in these other meetings have included: Diana Laurillard, Spyros Papadakis, Chris Alexander, Liz Masterman, Sheila MacNeill, Scott Wilson, Yannis Dimitriadis, Peter Goodyear, John Hedberg, Gregor Kennedy, Paul Gagnon, Debbie Evans, Kumiko Aoki, Carlos Alario, Chris Campbell, Matthew Kearney, Ron Oliver, Shirley Agostinho, Lori Lockyer and others. The Larnaca Declaration authors are grateful to all their colleagues for their insights.

\section{REFERENCES}

AUTC Learning Design (2002). Predict - Observe - Explain: Designer's voice - Context. Retrieved from http://www.learningdesigns.uow.edu.au/exemplars/info/LD44/more/03Context.html

Conole, G. (2013). Designing for learning in an open world. New York, NY: Springer.

Conole, G., \& Culver, J. (2010). The design of cloud works: Applying social networking practice to foster the exchange of learning and teaching ideas and designs. Computers \& Education, 54(3), 679-692.

Dalziel, J. (2003). Implementing learning design: The learning activity management system (LAMS). In G. Crisp, D. Thiele, I. Scholten, S. Barker, \& J. Baron (Eds.), Interact, integrate, impact: Proceedings of the 20th Annual Conference of the Australasian Society for Computers in Learning in Tertiary Education. Adelaide, 7-10 December 2003. Retrieved from http://ascilite.org.au/conferences/adelaide03/docs/pdf/593.pdf

Dalziel, J. (2009). Prospects for learning design research and LAMS. Teaching English with Technology, 9(2), 1-4.

Dalziel, J., \& Dalziel, B. (2011). Adoption of learning designs in teacher training and medical education: Templates versus embedded content. In L. Cameron \& J. Dalziel (Eds.), Proceedings of the 6th International LAMS \& Learning Design Conference 2011: Learning design for a changing world (pp. 81-88).

Dalziel, J., Conole, G., Wills, S., Walker, S., Bennett, S. Dobozy, E., ... Bower, M. (2013). The larnaca declaration on learning design - 2013. Retrieved from www.larnacadeclaration.org

Hernández-Leo, D., Villasclaras-Fernández, E. D., Asensio-Perez, J. I., Dimitriadis, Y., Jarrín-Abellán, I. M., Ruiz-Requies, I., \& Rubia-Avi, B. (2006). COLLAGE: A collaborative learning design editor based on patterns. Educational Technology and Society, 9, 58-71.

IMS GLC (2003). Learning design specification. Retrieved from http://www.imsglobal.org/ learningdesign/

Koper, E. J. R. (2001). Modelling units of study from a pedagogical perspective: The pedagogical metamodel behind EML. Heerlen: Open Universiteit Nederland. Retrieved from http://eml.ou.nl/ introduction/docs/ped-metamodel.pdf 


\section{J. DALZIEL}

Laurillard, D., \& McAndrew, P. (2002). Virtual teaching tools: Bringing academics closer to the design of e-learning. Retrieved from http://kn.open.ac.uk/public/getfile.cfm?documentfileid=7517

\section{James Dalziel}

Macquarie E-Learning Centre Of Excellence (MELCOE)

Macquarie University in Sydney, Australia 


\author{
PETER GOODYEAR, KATE THOMPSON, DAVID ASHE, ANA \\ PINTO, LUCILA CARVALHO, MARTIN PARISIO, PAUL PARKER, \\ BEAT SCHWENDIMANN, DEWA WARDAK AND PIPPA YEOMAN
}

\title{
2. ANALYSING THE STRUCTURAL PROPERTIES OF LEARNING NETWORKS
}

\author{
Architectural Insights into Buildable Forms
}

\begin{abstract}
OVERVIEW
A good repertoire of methods for analysing and sharing ideas about existing designs can make a useful contribution to improving the quality and efficiency of educational design work. Just as architects can improve their practice by studying historic and contemporary buildings, so people who design to help people learn can get better at what they do by understanding the designs of others. Moreover, new design work often has to complement existing provision, so the sensitive analysis of what already exists is an essential part of enhancing, rather than undermining, prior work (Goodyear \& Dimitridis, 2013). Since many factors can affect what and how people learn, the scope of analysis for design is broad. In fact, it has to go beyond what has been explicitly designed for learning, to take into account the various configurations of things, places, tasks, activities and people that influence learning. Part of the skill of analysis is knowing how to put a boundary on what one studies (Hutchins, 2010). We believe that analysis of this kind can help improve the design of all kinds of technology-enhanced learning (TEL) systems. But to focus our argument, this chapter draws on our recent collaborative analyses of learning networks (Carvalho \& Goodyear, 2014). Our thinking has been influenced quite strongly by the writings of Christopher Alexander on the properties that 'give life' to places and artefacts. The first part of the chapter has an ontological function - since analysis involves some decisions about the nature of the existence of its objects of inquiry. The second part illustrates the application of some of Alexander's ideas to the analysis of the structural properties of learning networks, where the goal of analysis is to inform design.
\end{abstract}

\section{NETWORKED LEARNING AND LEARNING NETWORKS}

\section{Networked Learning}

The empirical and conceptual work in which we are collectively engaged is located within the field of 'networked learning' (Steeples \& Jones, 2002; Goodyear et al., 
2004; Wenger, Traynor, \& de Laat, 2011; Carvalho \& Goodyear, 2014). The term 'networked learning' is used to denote situations in which people collaborate in a shared enterprise of knowledge creation, using digital communications technologies (such as email, online forums or blogs) to support much of their interaction. ${ }^{1}$ Our conception of learning and knowledge creation is very broad and we deliberately choose for analysis learning networks that test the boundaries of conventional ideas about what it means to come to know. For example, changing one's sense of self as a by-product of engaging in a collective project falls within our definition of networked learning. So does contributing new-to-the-world knowledge in a distributed scientific research project. ${ }^{2}$

A sense of sustained engagement with others is an important part of this conception of networked learning. It is hard to pin this down precisely. The act of looking something up on Wikipedia would not, in itself, constitute networked learning (in our view). Collaborating with other people to create and improve Wikipedia entries probably would.

Networked learning is sometimes set within programs of formally organised educational provision ${ }^{3}$ but that need not be the case. There are numerous examples of informal learning networks and of networks that provide learning and development opportunities within and between business organisations (Harasim et al., 1997). Many of the activities that James Gee (2005) associates with online 'affinity spaces' overlap with those that we call 'networked learning'. We deliberately speak of learning because we have a particular commitment to improving design for learning, rather than to the more diffuse goal of designing attractive affinity spaces. This helps sharpen the sense of what (structurally) is available to be analysed.

\section{Learning Networks}

We focus on 'learning networks' rather than 'affinity spaces' or 'learning communities'. Affinity spaces, according to Gee, are the places or sets of places (usually online) in which people congregate to partake of a shared endeavour. The focus is on place and activity. Learning communities, according to Wenger et al., are defined by membership, identity and shared history. The focus is on social relations and activity. When we speak of 'learning networks' we include place, membership, identity, history and activity. We also acknowledge the fluidity and changing topology of networks. But most of all, our interest in design for learning means that we also pay close attention to the epistemic purposes of the network - what is it that participants in the network are coming to know? In other words, our curiosity is influenced by a desire to understand how to design for networked learning.

The term 'learning network' has been in common use since the late 90s (Harasim et al., 1997; Mayadas, 1997). It is normally taken to include people and their relations and also (digital) tools and artefacts of various kinds. At that time, collaborating over the Internet was new enough for its most obvious roles, artefacts and technologies to 
be taken as the norm: students, instructors, experts; course notes, libraries; desktop computers, modems, cables, etc. As time has passed and technology developed, the conception of a learning network has become less clear cut - multiple people in diffuse roles can collaborate and communicate in multiple ways using a miscellany of devices and online artefacts. The networks we have analysed vary considerably in scale and complexity (Carvalho \& Goodyear, 2014). Some of the more complex examples involve multiple software platforms, diverse sets of activities ('activity bundles'), hundreds of online artefacts and thousands of participants. They have evolved over several years. Mapping them is a demanding task and the resulting maps occasionally surprise the people who manage the networks concerned (Pinto, 2014). Looking at such learning networks feels more like visiting a town or city than examining the simple artefacts, interfaces or activities that are the standard fare of TEL design.

\section{Approaches to the Analysis of Learning Networks}

Over the last 40 years or so, there has been a deepening interest in network forms of organisation, across a number of areas of the human sciences (notably in sociology, economics, geography and management - see for example Haggett \& Chorley, 1969; Granovetter, 1983; Castells, 1996; Podolny \& Page, 1998; Borgatti \& Foster, 2003; Knappett, 2013). Researchers have developed, or appropriated, a number of tools for analysing and/or modelling selected characteristics of networks (see e.g. Barabási, 2002). A number of these tools and methods are used to describe topological features of networks. Within the smaller field of networked learning research, most of the analytic interest has focussed on the content of online discussion and on social network analysis (SNA): what is being said, and who is talking to whom (see e.g. de Laat et al., 2007).

Our analytic approach is somewhat different. SNA, and a number of other network mapping methods, are normally deployed to capture emergent phenomena in (learning) networks. Because we are particularly interested in design, we also need ways of identifying designed structures in learning networks, representing their salient qualities and also tracing connections between what has been designed and emergent activity. Like architects or urban geographers, we want to understand how 'built form' influences human activity.

For analytic purposes, we argue that it is valuable to study networked learning from at least two perspectives: (i) understanding the activity and experiences of participating individuals and (ii) understanding the qualities of the network itself. Neither of these, on its own, provides the insights necessary to inform good design.

Taking the participating individual's perspective makes it easier to understand how engagement in networked learning connects with the rest of a person's life. 
Inspired by Ole Dreier's work on understanding everyday life, Jean Lave (2012) criticizes the

common habits of limiting our research practice to one or two settings and looking at activity only within one setting at a time. [Dreier] insisted that tracing persons' movements across the various contexts of their everyday lives is necessary for understanding how participation changes in changing practice.

(Lave, 2012, p. 162, emphasis added)

If we want to understand the actual lived experience of networked learning from the perspective of those most closely bound up in it we need to take into account extensive networks of various kinds of things. It is a profound mistake to restrict analysis to that which 'exists' in 'cyberspace' - to ignore the qualities of the place in which a person is physically located, the tools and resources which come to hand in that place, or their face-to-face interactions with colleagues, friends and family (Goodyear \& Carvalho, 2013).

Learning networks cannot be understood, and design for learning networks cannot be informed solely by, the aggregated or averaged experiences of participating individuals. Learning networks have important qualities of their own, and not all of these are visible to network participants.

An analogy with urban architecture and planning helps make the point. The flows of people through city streets and squares can be modeled and predicted accurately from information about the morphology of the streets. This can be done independently of information about the starting points, goals and destinations of the individuals who are moving. There is a 'syntax of space' that can underpin such modeling, and predict both movement and the personal mental maps that people form as they navigate the city (Hillier, 1999; Zimring \& Dalton, 2003; Long \& Baran, 2012). We would argue that the practices involved in improving urban design are likely to fail if they neglect to tap, or rely solely on, the lived experiences of city dwellers. Similarly, analysing networked learning requires research into both (i) the activities, habitual practices and experiences of participating individuals and (ii) the structural qualities of networks themselves. What can be observed and measured at network level may be qualities that are 'designed in' ab initio, or may emerge during the life of the network, or (most often) are a mixture of both.

This interdependence of structures and individual action is crucial to understanding how learning networks function and evolve over time. Existing structures influence, but do not determine, the activities of people; the agency enjoyed by people is constrained, but rarely extinguished, by existing structures; over time, structures change in response to human action - they are built up, or worn down. ${ }^{4}$

\section{Analysis and Design for Learning}

The roles of analysis and design are not always well-articulated in recent writing on design for learning, yet their key relationships echo core concerns in both educational 
research and in the literature on (mainstream) design. In one of his most influential books, Bruner (1966) distinguished between descriptive theories of learning and prescriptive theories of instruction. The first analyses examples of learning, the second says what should be done to help people learn. In the mainstream design literature, Veermas and Dorst (2007) similarly talk about the tensions and ambiguities between description and prescription, going back decades into the very foundations of design methodologies.

Research on the art and science of design for learning necessarily recognises that some people, quite reasonably, take on responsibility for helping other people learn. Some of this responsibility is discharged through design. Its legitimacy depends, in part, on the legitimacy learners grant to designers and educators.

Analysis of learning networks provides descriptions of learning activity, and of the effects on learning activities of the situations in which it occurs. Reflection on these descriptions can produce ideas that designers may find useful. From an analytic perspective, we can investigate the entities involved in a network, their relations and boundaries in a way that is guided by the needs of design, for others. The analysis of learning networks can take a critical stance, but (in our view) 'analysis for design for learning' has to move beyond the critical, because of an ethical commitment to acting on behalf of learners - in part, to help people become more self-sufficient learners.

\section{STRUCTURAL PROPERTIES OF LEARNING NETWORKS}

When we analyse a learning network we focus on such things as the relationships between the people who are involved, the material environments in which they work or study, the digital and material tools and artefacts they are using, the activities which interest them and which hold them together. As we said earlier, such a heterogeneous network cannot easily be bounded. Rather, it is traced through links and nodes, with the analyst's attention drifting to local concentrations, or to distinctive or recurring configurations of elements.

The analyst wants to know what helps the network function - what gives it life. Analysis sometimes reveals that seemingly trivial details can be very important. It can simultaneously be the case that macro or high-level properties of the network are important. Sometimes, it is the alignment across scale levels that matters. For example, from very early studies in this field we know that the availability or absence of certain kinds of communicative tools can have powerful effects on the communication that does or does not happen. The choice to use email rather than an online discussion board can threaten to extinguish certain kinds of valued activities, such as sustained discussions (Goodyear \& Steeples, 1992; Tagg, 1992).

Analysis that can inform the practices of design for learning networks therefore needs to have methods for making sense of a wide variety of entities and their relationships. This includes methods from such areas as computer-interface design, 
information architecture, ergonomics and usability, learning needs analysis, pedagogy, cognitive and motivational psychology, and more. It is easy to get lost in the miscellany of methods and theories prevailing in these areas.

A complementary way of approaching the analysis of learning networks is to try to capture higher-level qualities that are shared by many examples of lively, active, productive networks. It is important to then be able to render these in ways which can actually inform the work of designers - not to stop at the level of vague abstractions or exhortations (e.g. 'keep the learners engaged').

We have been using Christopher Alexander's work on design patterns and pattern languages (Alexander, 1979; Alexander et al., 1977) for some time now (see e.g. Goodyear, 2005; Goodyear et al., 2004; Goodyear \& Retalis, 2010). In our recent analytic work, we have been taking inspiration from Alexander's exploration of the 'fundamental properties' which he says appear again and again in things which have life (Alexander, 2006, Vol1, esp. pp. 144-296). We are not alone among educational researchers in taking this step in the journey (see e.g. Bauer \& Baumgartner, 2010). However, we think we are succeeding in finding some particularly useful links between Alexander's thoughts and the properties of learning networks.

\section{Alexander, Analysis and Design}

Part of the appeal of Alexander's early work on design patterns arises from the way he conjures up images of convivial urban, working and domestic life, and from the architectural sensibility that allows him to relate human experience, activity and emotion to the qualities of the material world. Like most designers, he has a commitment to improving life through action in the material world. Unusually, he works across vast distances in scale and scope (from ornaments to geographical regions). His invention of the pattern language, which aligns designed elements across scale levels to meet the needs of a project, resonates nicely with the problems of design for learning, wherein we know that influential factors range across scales from 'neurons to neighborhoods' (IOM/NRC, 2012). Similarly, design for learning needs to be able to help align designed (and other) elements across scale levels.

Design is a way of balancing competing forces - of reconciling incompatible requirements, sometimes by reframing the situation so that the proposed solution meets deeper needs. For example, a theme running through Alexander's work is the need to design for the diverse wishes of autonomous individuals and for conviviality. His analysis of built forms - especially rooms, the transitional spaces around homes, and urban spaces - shows how privacy and community can be afforded simultaneously in good designs. The rest of this chapter provides two examples where we have drawn on Alexander's writing to guide our thinking about the analysis of learning networks. 


\section{First Example: Strong Centres}

As our first example, we take a major theme of Alexander's 2006 book The nature of order. Alexander's analysis is concerned with identifying the commonalities between forms that he describes as having 'more life' or 'greater wholeness' than similar forms which he, and other people in empirical studies, find less alive or whole. ${ }^{5}$ The early parts of his analysis, on which we draw, are primarily concerned with the qualities of artefacts and buildings. He identifies 15 fundamental properties (structural features) that he finds, in various combinations, in things that have 'more life'. These properties mostly pertain to visual perception - that is, they capture qualities that can be seen, such as levels of scale in the façade of a building, boundaries, local symmetries, deeply interlocking forms, etc. While visual perception is very salient here, Alexander is deeply concerned with other senses (especially touch) but, more importantly, he is concerned with how the structural properties of the place or artefact affect how we feel; how good we feel in its presence.

As we pointed out earlier, it is hard to find an exact boundary to a learning network. The essence of the network - what it is, for most of its participants - lies closer to its core than its margins. How does one find the centre (or centres) of a network, either as a participant or analyst? One traces participants' activity and finds the places where the discussions are most active, the links thickest, the talk most ontopic, the sharing most reciprocal. These are the places where the network is most alive, towards which people will gravitate and in which they are most likely to linger. Alexander speaks of 'strong centres' and indeed sees them as the most profound of the 15 properties. He describes how they appear and function in a variety of artefacts (like carpets and ceramics) and in buildings and more complex urban forms. He finds them more often in older, craft-based, objects and buildings than in the modern or mass-produced. Here, he illustrates the idea with an example from China:

The imperial inner city of Beijing has a centered quality. It is a layered system of nested domains which lead, one by one, to the inner city, and then to the inner sanctum of the inner city. The hierarchy of layers creates the deep feeling and intensity of the center: the deep center arises at the heart of the inner city, because of the field effect generated by the nesting. We pass through a series of zones of increasing intensity as we go into the building: the gradient of increasing intensity creates a center... (Alexander, 2006, p. 154-5)

And he contrasts this with the difficulty of finding strong centres in much of modern architecture, including modern western homes, where neither the fire, nor the kitchen, the TV or the bed are important enough to carry the role.

Within learning networks, we can sometimes see how patterns of activity point to where we might find a strong centre. Indeed, a peculiar characteristic of learning networks is that participant activity furnishes and indeed reshapes the landscape. An over-literal example is in shared virtual worlds, such as Second Life, where 
participants build, decorate and visit. But even in older spaces, such as with asynchronous discussion boards, the landscapes through which one navigates are partly formed from sedimented conversations.

Analysis of learning networks sometimes reveals silent, abandoned places. Sometimes it reveals intense activity. What is found, through such analysis, is of course a mix of original designed space and the traces of subsequent activity. If strong centres can be created and reinforced, in the original design, then one has reason to hope that activity will follow - that in their online work, people will gravitate towards places where it feels good to linger, and through their online activity will further furnish and add patina to the places where they feel most themselves.

In learning networks, then, how do we recognise such strong centres? And what do we need to know in order to help create them?

Our best guess is that something akin to Alexander's visual sensibility is analytically useful. This is partly because the dominant ways of interacting with and through an online learning network involve the visual. Most, if not all, of what we need to know, in order to navigate online, works in the visual mode. ${ }^{6}$ And apart from the special case of 3-D virtual worlds, our navigation is dependent on visual information that is organised in the 2-D plane of the computer screen. Alexander's examples of strong centres in built space assume an ability to move through space - to see as a person moving, rather than as a static observer. The strong centres he described in his example from Beijing really only work if one is passing through/into the spaces concerned. Is there an analogue in the 2-D plane that provides the interface to most online learning networks? How can screen layout help create strong centres?

At a minimum, this must mean that the screens/pages on which people most rely to help them navigate should give some clues about where life is to be found drawing one towards the centres of current or recent activity. If there is a variety of such places, then visual clues that nudge one this way or that (depending on current interest or mood) would be helpful. ${ }^{7}$ Of course, some normal rules of interface design apply: that one should not be forced to read detailed instructions, overdose on information, or have to think too hard about where to head - signs or sounds should beckon and suggest, leaving one's scarce mental resources free for the more demanding work of engaging in intelligent conversation (see also Long \& Baran, 2012 on the 'legibility' of built space).

The allusion to Second Life, above, raises questions about how long our 2-D interfaces will continue to provide the principal mode of interaction. Anyone thinking about the future of design for learning (and its analytic counterpart) is bound to wonder what may change, and what certainties will be shaken, when immersion in a virtual world, with speech and haptic interaction, becomes more common (Kirsh, 2013). Such thinking also needs to recognise that our immersion into the virtual world has a counterpart - as the digital infiltrates the material world (with mobile personal devices, tangibles, programmable objects, ambient intelligence, etc). In one way, this accelerating inter-penetration of the virtual and material worlds (Mitchell, 2003) simplifies the relations between Alexander's work and our own. When there 
ceases to be a sharp distinction between the virtual and the material, then design and analysis can operate more uniformly, albeit across heterogeneous networks.

\section{Second Example: Rapid Urbanisation and the MOOC Phenomenon}

Networked learning is getting more attention right now than it has for a decade or so - the main reason being that staff associated with a number of prestigious universities are offering so-called MOOCs - Massive Open Online Courses (OBHE, 2012; Kay et al., 2013). Anyone summarising the central tendencies in the networked learning literature till recently might well have come to the view that learning networks in formal education involve rather small numbers of learners (tens to small numbers of hundreds) to which the design metaphor of the 'virtual classroom' might fairly be applied. Associated design elements include such things as a 'virtual café' (where learners can discuss whatever they wish to discuss, not just matters relating directly to a course), and 'notice boards', where important announcements can be posted. The scale is cosy and bijou, if a little self-conscious and awkward.

Networked learning design elements that work (reasonably well) at such small scale are suddenly challenged by the MOOC phenomenon - rather as if the hamlet had become a town of 100,000 people, without much consideration of the need for new kinds of building or infrastructure. What options are there for aligning designed elements to the needs of a town rather than a village? On one view, MOOCs pretty much ignore the social. The core idea in such a design is that an expert lecturer makes available videos of themselves presenting mini-lectures, and learners watch and listen. There need be no social organisation, beyond distinguishing the lecturer from the student, the preacher from the congregation, or the rock star from the audience. At one level up, in the design/evolutionary chain, students can be allocated to small study groups - either on a random or algorithmic basis. When they work well, these groups can help with peer feedback and various kinds of study support. But they are often just a cloning of the virtual classroom - tens or hundreds of identical rooms, with students allocated to rooms (not necessarily to groups) on an arbitrary basis. A less managerialist approach would let students pick their own groups - but if the rooms are all the same, and the information about group members is sketchy, what kind of choice is this? One is either a prisoner, or lost in the city. A cyberurban anomie, as much as wishful thinking at enrolment time, might explain the high disengagement rates found in many MOOCs.

How might this be done better? What kinds of ideas and experiences, what analytic and design constructs could help, when thinking about the 'rapid urbanisation' that MOOCs represent?

Alexander writes a lot about convivial life in towns and cities (see especially the first half of A Pattern Language). His ways of analysing what works in convivial, human, lively urban spaces, make it easy to spot what is missing with the identical, cloned spaces of a MOOC. One might say he is at his best when he is analysing the success of small public squares, street cafes, beer halls, self-governing workshops, 
food stands and bus stops. He can explain why different activities cluster together, at what spatial intervals, and how people gravitate to places that make them feel good. From this, he can generate design constraints that help with the creation or repair of living spaces - such as by limiting the height of buildings in which people are to live (four floors), or the amount of land zoned for parking $(<9 \%)$, or the minimum distance between corner grocery stores (200 yards). He also writes about the two opposite ways in which built form can supress human social activity - by imposing structural form so that social activity has to adjust to its needs, or by offering so little structure that social activity feels it has lost its place (Alexander et al., 1977, p. 941-5). Space that is too rigid or too flexible can be damaging (cf. Boys, 2011).

In an early, highly regarded paper on problems in the planning of new cities, Alexander (1966) observed a crucial difference between organically-developing ('natural') cities and many of those 'artificial' cities being constructed to the designs of urban planners. Looking more deeply into the structural differences, he discerned that the new designs commonly made use of simplifying strategies (a 'compulsive desire for neatness and order') that resulted in sharply segregated uses for space. In contrast, many of the spaces in organically-developing cities typically involve the overlap of several different systems of activity, giving depth and richness and also mutually-reinforcing patterns that help each area of activity prosper. (One of his examples is of how urban zoning regulations, intended to separate residential and industrial activities, make it hard for small (home-based) businesses to start up.)

What has this to do with MOOCs? Some of the more innovative possibilities being explored by MOOC platform developers include a combination of learning analytics and artificially-intelligent agents to provide more targeted pedagogical support for learners (see e.g. Kay et al., 2013; Daradoumis et al., 2013). The logic behind this is one which foregrounds teaching. In contrast, or in addition, one might choose to foreground space - to think about ways of enhancing the experience of MOOCs that resonate with ways we experience the buzz of a vibrant city. After all, MOOCs bring together thousands of people with shared interests and diverse backgrounds. The simplifying tendency identified by Alexander would be reflected in MOOC providers using learning analytics data to cluster people together around shared profiles - 'the mania every simple-minded person has for putting things with the same name into the same basket' (Alexander, 1966, p. 13). It might be better to use intelligent software to generate online spaces within each of which several activity systems, of interest to diverse groups of people, overlap (Alexander, 1999). For the technically-minded, production of such spaces needs to be guided by the creation of semi-lattice, rather than tree-like, forms.

It must be emphasised, lest the orderly mind shrink in horror from anything that is not clearly articulated and categorised in tree form, that the ideas of overlap, ambiguity, multiplicity of aspect, and the semi-lattice, are not less orderly than the rigid tree, but more so. They represent a thicker, tougher, more subtle and more complex view of structure. (op. cit., p. 9-10) 
MOOCs are not necessarily privatizing; their use does not have to entail individualized and isolated learning experiences. Indeed, the earliest MOOCs (cMOOCs rather than xMOOCs) had a strong, collaborative, community-oriented design philosophy (Clarà \& Barberà, 2013). Some recent work with xMOOCs at the Ecole Polytechnic Federale de Lausanne has been experimenting with complementary, face-to-face study groups (Li et al., 2014).

The insight we take from Alexander's work is that the generation of spaces suited to more convivial interactions in and around MOOCs would be (a) worthwhile, (b) best approached in terms of helping people find the kinds of places and activity bundles in which they would like to engage, rather than simply trying to find like-minded others. Such evidence as we have in the still rather scant MOOCs literature suggests that participation in collaborative activities in cMOOCs is not necessarily straightforward (Mackness et al., 2010), and that some structuring resources (such as 'legible places') might be very helpful to people who are struggling to organize their work. And while the face-to-face study groups investigated in the EPFL research (Li et al., 2014) seem to be a useful complement to online lectures, they are not straightforwardly replicable or scalable outside a formal education context. Alexander's influence on our design imagination is not of a kind that can quickly specify solutions for some of the issues being experienced with MOOCs. Instead, it helps us see that there might be more creative ways of thinking about large-scale online learning: not so much a global classroom as a learning city.

\section{CONCLUDING COMMENTS}

In this chapter, we have tried to show how the judicious translation of some ideas about built form, derived mainly from the work of Christopher Alexander, can guide the analysis of learning networks, and especially of the designed structures they can inhabit. We see three lines of connection between these ideas and their application in the analysis of structures in networked learning. First, there is what we referred to as the literal-virtual connection - such as when networked learning is housed in Second Life. Then there is the emerging-hybrid connection - where we stop seeing the virtual and material worlds as separate, and think more carefully about designs that help integrate activity across increasingly complex and heterogeneous spaces. Thirdly, there is a more metaphorical connection, in which our understanding of how people perceive and navigate in built space can be translated and used to design interfaces to virtual spaces. For example, we might argue that many of the spaces inhabited by today's learning networks are so structurally simple and lacking in texture that they stimulate only a very narrow range of activities and interactions. To this we might add that the navigation of more complex spaces is overly dependent on maps and signposts - on texts rather than visual cues - such that the poor legibility of online spaces limits the design imagination. 


\section{ACKNOWLEDGEMENTS}

\section{The authors gratefully acknowledge the financial support of the Australian Research Council through Laureate Fellowship grant FL100100203.}

\section{NOTES}

1 The main ideas and educational practices associated with networked learning go back to the 1970 s, if not earlier. Ivan Illich's provocative writings about 'learning webs' are often cited as an early source. They contain some striking thoughts about repurposing some emerging technologies (see e.g. Illich, 1971, p. 75 ff.). Alexander draws on Illich's ideas in describing his 'Network of Learning' design pattern (Alexander et al., 1977, p. 99-103). The wave of writing based on early experiments with 'computer-mediated communication' (CMC) in the late $1980 \mathrm{~s}$ is also worth consulting for some foundational ideas (see e.g. Mason \& Kaye, 1989; Riel \& Levin, 1990; Kaye, 1992). See also early writing on network technologies for collaboration in business such as Schrage (1990).

2 Jean Lave remarks on "the commonplace ways in which we too easily collapse "learning" into "acquisition of knowledge," as a decontextualized end in itself. When we take a relational perspective, "knowledge" or "knowledge-ability" must be understood as part of, and as taking meaning from and for, persons engaged as apprentices to their own changing practice across the multiple contexts of their lives' (Lave, 2012, p. 167). (Cf. Ingold who speaks of learning as improvising movement along a way of life.)

3 Much of the early literature on networked learning was written by university-based teachers who were pioneering such approaches. Their educational philosophies and pedagogical approaches were often inspired by ideas that did not sit comfortably with prevailing notions of how formal higher education should be done. The resulting literature sometimes underplays the shaping effects of university rules and power relations on students' activity.

4 The same is true of a very wide variety of human activity (Giddens, 1984). John Law expands on the point in relation to analyzing networks: “... it is necessarily important to distinguish people from artefact ... such objects are understood as being shaped by humans. And in turn they produce a context, a geography or an architecture which enables and/or constrains subsequent human projects. ... entities, things, people, are not fixed. Nothing that enters into relations has fixed significance or attributes in and of itself. Instead, the attributes of any particular element in the system, any particular node in the network, are entirely defined in relation to other elements in the system, to other nodes in the network. And it is the analyst's job, at least in part, to explore how those relations - and so the entities that they constitute - are brought into being" (Law 2006).

5 For another example of our analysis, along these lines, see Thompson \& Kelly (2012)

6 There have been some interesting experiments with 3-D audio in virtual worlds which could be interesting to pursue here.

7 The increasingly common use of more complex and/or subtle forms of navigation control, such as through touch pads, touch screens, multi-touch tables, kinect sensors etc., means that the design issue is not so strongly related to visual perception. We imagine that visual cues to trigger more complex touch/gestural navigational moves will become the norm.

\section{REFERENCES}

Alexander, C. (1966). A city is not a tree. Design, 126.

Alexander, C. (1979). The timeless way of building, New York, NY: Oxford University Press.

Alexander, C. (1999). The origins of pattern theory: The future of the theory and the generation of a living world. IEEE Software, 16, 71-82.

Alexander, C. (2006). The nature of order. Berkeley, CA: Center for Environmental Structure.

Alexander, C., Ishikawa, S., Silverstein, M., Jacobson, M., Fiksdahl-King, I., \& Angel, S. (1977). A pattern language: towns, buildings, construction. New York, NY: Oxford University Press. 
Barabási, A. L. (2002). Linked: The new science of networks. Cambridge, MA: Perseus Publishing.

Bauer, R., \& Baumgartner, P. (2010). The potential of Christopher Alexander's theory and practice of wholeness: Clues for developing an educational taxonomy. EuroPLoP' 10 Proceedings of the 15th European Conference on Pattern Languages of Programs.

Borgatti, S., \& Foster, P. (2003). The network paradigm in organizational research: A review and typology. Journal of Management, 29, 991-1013.

Boys, J. (2011). Towards creative learning spaces: Re-thinking the architecture of post-compulsory education, New York, NY: Routledge.

Carvalho, L., \& Goodyear P., (Eds.), (2014). The architecture of productive learning networks. New York, NY: Routledge.

Castells, M. (1996). The rise of the network society, Oxford: Blackwell.

Clarà, M., \& Barberà, E. (2013). Learning online: Massive open online courses (MOOCs), connectivism, and cultural psychology. Distance Education, 34(1), 129-136.

Daradoumis, T., Bassi, R., Xhafa, F., \& Caballe, S. (2013). A review on massive e-learning (MOOC) design, delivery and assessment. Eighth International Conference on P2P, Parallel, Grid, Cloud and Internet Computing (3PGCIC), 208-213. doi: 10.1109/3PGCIC.2013.37

de Laat, M., Lally, V., Lipponen, L., \& Simons, R. J. (2007). Online teaching in networked learning communities: A multi-method approach to studying the role of the teacher. Instructional Science, 35, $257-286$.

Fenwick, T., Edwards, R., \& Sawchuk, P. (2011). Emerging approaches to educational research: Tracing the sociomaterial. Abingdon: Routledge.

Gee, J. (2005). Semiotic social spaces and affinity spaces: From the age of mythology to today's schools. In D. Barton \& K. Tusting (Eds.), Beyond communities of practice: Language, power and social context. Cambridge, UK, Cambridge University Press.

Giddens, A. (1984). The constitution of society: Outline of the theory of structuration. Berkeley, CA, University of California Press.

Goodyear, P. (2002). Online learning and teaching in the arts and humanities: Reflecting on purposes and design. In E. A. Chambers \& K. Lack (Eds.), Online conferencing in the arts and humanities (pp. 1-15). Milton, Keynes: Institute of Educational Technology, Open University.

Goodyear, P. (2005). Educational design and networked learning: patterns, pattern languages and design practice. Australasian Journal of Educational Technology, 21, 82-101.

Goodyear, P., \& Carvalho, L. (2013, September). The analysis of complex learning environments. In H. Beetham \& R. Sharpe (Eds.), Rethinking pedagogy for a digital age: Designing and delivering e-learning. New York,NY: Routledge.

Goodyear, P., \& Dimitriadis, Y. (2013). In medias res: Reframing design for learning. Research in Learning Technology, 21.

Goodyear, P., \& Steeples, C. (1992). IT-based open learning: Tasks and tools. Journal of Computer Assisted Learning, 8(3), 163-176.

Goodyear, P., Banks S., Hodgson V., \& McConnell D. (Eds.). (2004a). Advances in research on networked learning. Dordrecht, The Netherlands: Kluwer Academic Publishers.

Goodyear, P., Avgeriou, P., Baggetun, R., Bartoluzzi, S., Retalis, S., Ronteltap, F., \& Rusman, E. (2004b), Towards a pattern language for networked learning. In S. Banks, P. Goodyear, V. Hodgson, C. Jones, V. Lally, D. McConnell, \& C. Steeples, (Eds.), Networked learning 2004. Lancaster: Lancaster University.

Granovetter, M. (1983). The strength of weak ties: A network theory revisited. Sociological Theory, 1, 201-233.

Haggett, P., \& Chorley, R. J. (1969). Network analysis in geography. London, UK: Edward Arnold.

Harasim, L., Hiltz, S., Teles, L., \& Turoff, M. (1997). Learning networks: A field guide to learning and teaching online. Cambridge, MA: MIT Press.

Hillier, B. (1999). Space is the machine: A configurational theory of architecture. Cambridge, UK: Cambridge University Press.

Hutchins, E. (2010). Cognitive ecology. Topics in Cognitive Science, 2, 705-715.

Illich, I. (1971). Deschooling society. New York, NY: Harper Row. 


\section{P. GOODYEAR ET AL.}

IOM (Institute of Medicine) and NRC (National Research Council) (2012). From neurons to neighborhoods: An update: Workshop summary. Washington, DC: The National Academies Press.

Jones, C. (2004). Networks and learning: Communities, practices and the metaphor of networks. ALT-J, $12,81-93$.

Kay, J., Reimann, P., Deibold, E., \& Kummerfeld, B. (2013). MOOCs: So many learners, so much potential. IEEE Intelligent Systems, 28(3), 70-77.

Kaye, A. (Ed.). (1992). Collaborative learning through computer conferencing: The Najaden papers. Berlin, Germany: Springer Verlag.

Kirsh, D. (2013). Embodied cognition and the magical future of interaction design. ACM Transactions on Computer-Human Interaction, 20, 1-30.

Knappett, C. (Ed.). (2013). Network analysis in archaeology: New approaches to regional interaction, Oxford, UK: Oxford University Press.

Lave, J. (2012). Changing practice. Mind, Culture, and Activity, 19, 156-171.

Law, J. (2006). Networks, relations, cyborgs: On the social study of technology. In S. Read \& C. Pinilla (Eds.), Visualizing the invisible: Towards an urban space. Amsterdam, The Netherlands: Techne Press.

Li, N., Verma, H., Skevi, A., Zufferey, G., \& Dillenbourg, P. (2014). MOOC learning in spontaneous study groups: Does synchronously watching videos make a difference? European MOOCs Conference. Retrieved from http://infoscience.epfl.ch/record/196608/files/nanli_submission\%20(Last\%20Version).pdf

Long, Y., \& Baran, P. K. (2012). Does intelligibility affect place legibility? Understanding the relationship between objective and subjective evaluations of the urban environment. Environment and Behavior, 44, 616-640.

Mackness, J., Mak, S. \& Williams, R. (2010). The ideals and reality of participating in a MOOC. Networked learning conference. Lancaster, UK: University of Lancaster.

Mason R., \& Kaye A., (Eds.), (1989). Mindweave: Communication, computers and distance education, Oxford, UK: Pergamon.

Mitchell, W. J. (2003). Me++: The cyborg self and the networked city. Cambridge, MA: MIT Press.

Observatory on Borderless Higher Education. (2012, October). MOOCs and disruptive innovation: The challenge to HE business models. Retrieved from http://www.obhe.ac.uk/documents/view details?id $=929$

Pinto, A. (2014). Design and the functioning of a productive learning network. 9th International Conference on Networked Learning 2014, Edinburgh: Networked Learning Conference Organiser.

Podolny, J., \& Page, K. (1998). Network forms of organization. Annual Review of Sociology, 24, 57-76.

Riel, M. M., \& Levin, J. A. (1990). Building electronic communities: Success and failure in computer networking. Instructional Science, 19, 145-169.

Schrage, M. (1990). Shared minds: The new technologies of collaboration. New York, NY: Random House.

Steeples C., \& Jones C. (Eds.). (2002). Networked learning: Perspectives and issues. London, UK: Springer.

Tagg, A. (1992). Computer conferencing systems and their application: A suggested methodology. London: Birkbeck College, University of London.

Thompson, K., \& Kelly, N. (2012). Combining collaboration spaces: Identifying patterns of tool use for decision-making in a networked learning environment. 8th International Conference on Networked Learning, Maastricht, Netherlands.

Wenger, E., Trayner, B., \& de Laat, M. (2011). Promoting and assessing value creation in communities and networks: A conceptual framework. Heerlen, Netherlands: Ruud de Moor Centrum, Open Universiteit of the Netherlands.

Zimring, C., \& Dalton, R. C. (2003). Linking objective measures of space to cognition and action. Environment and Behavior, 35, 3-16. 
Peter Goodyear,

Centre for Research on Computer Supported Learning and Cognition (CoCo) University of Sydney, Australia

David Ashe,

Centre for Research on Computer Supported Learning and Cognition (CoCo) University of Sydney, Australia

Lucila Carvalho,

Centre for Research on Computer Supported Learning and Cognition (CoCo)

University of Sydney, Australia

Martin Parisio,

Centre for Research on Computer Supported Learning and Cognition (CoCo)

University of Sydney, Australia

Paul Parker,

Centre for Research on Computer Supported Learning and Cognition (CoCo) University of Sydney, Australia

Ana Pinto,

Centre for Research on Computer Supported Learning and Cognition (CoCo) University of Sydney, Australia

Kate Thompson,

Centre for Research on Computer Supported Learning and Cognition (CoCo)

University of Sydney, Australia

Dewa Wardak

Centre for Research on Computer Supported Learning and Cognition (CoCo) University of Sydney, Australia

Pippa Yeoman

Centre for Research on Computer Supported Learning and Cognition (CoCo)

University of Sydney, Australia

Beat Schwendimann

École Polytechnique Fédérale de Lausanne, Switzerland 